\title{
One Target, Two Mechanisms: The Impact of 'Candidatus Liberibacter asiaticus' and Its Vector, Diaphorina citri, on Citrus Leaf Pigments
}

\author{
Nabil Killiny ${ }^{1}$ and Yasser Nehela ${ }^{1,2}$ \\ ${ }^{1}$ Department of Plant Pathology, Citrus Research and Education Center, University of Florida, 700 Experiment Station Rd., Lake \\ Alfred 33850, U.S.A.; and ${ }^{2}$ Department of Agricultural Botany, Faculty of Agriculture, Tanta University, Tanta, Egypt \\ Accepted 29 March 2017.
}

\begin{abstract}
Huanglongbing (HLB) is currently the largest threat to global citrus production. We examined the effect of HLB pathogen 'Candidatus Liberibacter asiaticus' infection or infestation by its vector, Diaphorina citri, on 'Valencia' sweet orange leaf pigments using high-performance liquid chromatography, followed by gene expression analysis for $\mathbf{4 6}$ involved genes in carotenoid and chlorophyll biosynthesis pathways. Both ' $\mathrm{Ca}$. L. asiaticus' and $D$. citri alter the total citrus leaf pigment balance with a greater impact by ' $\mathrm{Ca}$. L. asiaticus'. Although zeaxanthin was accumulated in ' $C a$. $\mathbf{L}$. asiaticus'-infected leaves, chlorophyllide $a$ was increased in $D$. citri-infested plants. Our findings support the idea that both ' $\mathrm{Ca}$. L. asiaticus' and $\mathrm{D}$. citri affect the citrus pigments and promote symptom development but using two different mechanisms. ' $\mathrm{Ca}$. L. asiaticus' promotes chlorophyll degradation but accelerates the biosynthesis of carotenoid pigments, resulting in accumulation of abscisic acid and its precursor, zeaxanthin. Zeaxanthin also has a photoprotective role. By contrast, $D$. citri induced the degradation of most carotenoids and accelerated chlorophyll biosynthesis, leading to chlorophyllide $a$ accumulation. Chlorophyllide $a$ might have an antiherbivory role. Accordingly, we suggest that citrus plants try to defend themselves against ' $\mathrm{Ca}$. L. asiaticus' or $\mathrm{D}$. citri using multifaceted defense systems, based on the stressor type. These findings will help in better understanding the tritrophic interactions among plant, pathogen, and vector.
\end{abstract}

Infection by pathogenic bacteria, fungi, oomycetes, and viruses can cause morphological, biochemical, and physiological alterations in the host plant (Lobato et al. 2010; Prokopová et al. 2010 a,b; Rosales and Burns 2011; Wei et al. 2014a,b; Xie et al. 2011). Photosynthesis is one of the most affected physiological processes in the autotrophic life of the infected plants (Kangasjärvi et al. 2012; Lobato et al. 2010; Prokopová et al. 2010 a,b). For example, both tomato genotypes Lycopersicon chmielewskii (moderately resistant) and L. esculentum (susceptible) showed a deterioration of photosynthesis after infection by powdery mildew fungus Oidium neolycopersici (Prokopová et al. 2010a). Furthermore, in lettuce plants (Lactuca sativa) infected by Bremia lactucae, the oomycete pathogen of lettuce

Corresponding author: N. Killiny; Telephone: +1 863.956.8833; E-mail: nabilkilliny@ufl.edu

*The $\boldsymbol{e}$-Xtra logo stands for "electronic extra" and indicates that two supplementary tables are published online.

@ 2017 The American Phytopathological Society downy mildew, increased nonphotochemical quenching, deficiency in photosynthetic pigment content, electron transport of photosystem II $\left(\Phi_{\mathrm{PSII}}\right)$, and the maximal quantum yield of PSII $\left(\mathrm{F}_{\mathrm{V}} / \mathrm{F}_{\mathrm{M}}\right)$ were reported (Prokopová et al. 2010b).

Many factors can affect the rate of photosynthesis, such as light intensity, $\mathrm{CO}_{2}$ concentration, and photosynthetic pigment content of the leaves (Smith 1938; Terry 1980). The photosynthetic pigments are responsible for the absorption of light energy through the light-dependent reactions phase of photosynthesis (Gough et al. 2003; Lobato et al. 2010; Tanaka et al. 2011). The photosynthetic pigments include the chlorophyll, carotenoids, and other pigments (Lobato et al. 2010).

Chlorophylls are the most abundant pigments in higher plants (Gough et al. 2003; Reinbothe et al. 2010; von Wettstein et al. 1995). The structure of chlorophylls are tetrapyrrole macrocycles (porphyrin rings) containing $\mathrm{Mg}^{+2}$ in the center, a phytol chain, and a characteristic fifth ring consisting of a methyl group, as in chlorophyll $a$, or a formyl group, as in chlorophyll $b$ (Tanaka and Tanaka 2007; von Wettstein et al. 1995). Chlorophylls play a key role in photosynthesis by harvesting sunlight energy and transferring the electrons to the other molecules in the reaction center (Reinbothe et al. 2010; Tanaka and Tanaka 2007; Tanaka et al. 2011). In addition, chlorophyll derivatives such as chlorophyllide result from the removal of the phytol chain by chlorophyllase, a hydrolase common in most plants that is located in the endoplasmic reticulum (ER) and tonoplast $(\mathrm{Hu}$ et al. 2015). Chlorophyllide was found to be formed after herbivory or when chlorophyllase was freed from the ER by cell disruption. Its toxicity plays a critical defense role against chewing insects such as Spodoptera litura (Hu et al. 2015) and the necrotrophic fungus Alternaria brassicicola (Kariola et al. 2005 ) in Arabidopsis thaliana plants.

Carotenoids are a large group of tetraterpenoids that are produced from eight isoprene molecules and contain 40 carbon atoms with polyene chains that may contain up to 15 conjugated double bonds (Tanaka et al. 2008; Vershinin 1999). In higher plants, carotenoids are synthesized in the chloroplasts and chromoplasts by nuclear-encoded enzymes (Cazzonelli 2011; Cunningham and Gantt 1998; Tanaka et al. 2008). Although there are over 700 different known carotenoids (Kato 2012), only 115 carotenoid compounds were identified in citrus fruit (Matsumoto et al. 2007; Rouseff et al. 1996). Carotenoids are divided into two classes: carotenes, which are purely hydrocarbons and do not contain $\mathrm{O}_{2}$, and xanthophylls, which contain $\mathrm{O}_{2}$. In higher plants, carotenoids play an important role in the variegation of leaves, flowers, fruit, and other organs (Cazzonelli 2011; Tanaka et al. 2008). Additionally, they serve as norisoprenoid precursors for many biologically important 
compounds (Bauernfeind 1972; Tanaka et al. 2008; Vershinin 1999). Carotenoids with unsubstituted $\beta$-ionone rings (such as $\alpha$-carotene, $\beta$-carotene, $\beta$-cryptoxanthin, and $\gamma$-carotene) are precursors for vitamin $\mathrm{A}$ and can also act as antioxidants (Bauernfeind 1972; Cunningham and Gantt 1998). Furthermore, carotenoids are not only responsible for the specific coloration patterns in plants but also have a main role in the photosynthetic process (Armstrong and Hearst 1996; Vershinin 1999). Carotenoids protect chlorophyll pigments from photodamage, in addition to their role as accessory light-harvesting pigments in all plants, while they absorb light energy for the use in photosynthesis (Armstrong and Hearst 1996; Vershinin 1999).

Huanglongbing (HLB), also known as citrus greening disease, the most serious disease in citrus, originated in East Asia at the end of 1800s (Bové 2006; da Graça and Korsten 2004; Gottwald 2010; Gottwald et al. 1989). HLB is caused by the fastidious phloem-restricted bacterium 'Candidatus Liberibacter spp.', a member of the gram-negative $\alpha$-proteobacteria, and is currently not available in culture (Bové 2006; Gottwald 2010; Jagoueix et al. 1994). Taxonomically, based on the characteristic $16 \mathrm{~S}$ ribosomal DNA sequences and geographical distribution, three 'Ca. L. spp.' have been proposed: 'Candidatus Liberibacter asiaticus' in Asia (Bové and Ayres 2007; Gottwald 2010; Wang and Trivedi 2013), 'Ca. L. africanus' in Africa (da Graça 1991; Planet et al. 1995), and ' $\mathrm{Ca}$. L. americanus' in Brazil (ColettaFilho et al. 2004; do Carmo Teixeira et al. 2005a). Among the three Liberibacter spp., ' $C a$. L. asiaticus' is the most dominant species and has caused huge economic losses to citrus production worldwide (Bové 2006; Gottwald 2010). The tree-totree transmission of the bacterium occurs by grafting infected material or by psyllid vectors: the Asian citrus psyllid Diaphorina citri Kuwayama (Hemiptera: Liviidae) in Asia and the Americas (Bové 2006; Gottwald 2010; Wang and Trivedi 2013) and the African psyllid Trioza erytreae (Del Guercio) in Africa (da Graça 1991). These two vectors are responsible for the wide geographical distribution of HLB disease in the infected areas (do Carmo Teixeira et al. 2005b).

The characteristic symptoms of HLB-infected citrus trees are due to alteration in many physiological aspects such as phytohormonal levels, carbohydrate status (Rosales and Burns 2011), and carotenoid content (Wei et al. 2014a,b). Symptoms of HLB are induced by both the pathogen and its vector, and include blotchy mottle and yellow veins on leaves (Bové 2006; Schneider 1968). In addition, young flushes on infected trees appear yellow, with small and upright leaves showing various chlorotic patterns (Bové 2006; da Graça 1991; Sagaram et al. 2009; Schneider 1968). These symptoms are usually visible only on some branches of the tree, whereas other branches are nonsymptomatic (Schneider 1968). Stunted growth, twig dieback, and poor flowering are secondary HLB symptoms (Bové 2006; Mishra et al. 2011; Schneider 1968). The fruit from the infected trees are small, lopsided, and distorted, with color inversion (Bové 2006; Mishra et al. 2011), and often contain abnormal and brown seed. Furthermore, the fruit yield of infected trees decreases until the trees become nonproductive, whereas juvenile infected trees may never bear fruit (Sagaram et al. 2009).

On the other hand, D. citri feeding causes waxy deposits, sugary honeydew, and sooty mold. High populations of psyllids feeding on new shoots can kill the growing flush. Feeding of a moderate psyllid population can result in deformation of leaves and shoots, twisted leaves, and asymmetrical yellowing on leaves (Hoy and Nguyen 2000). In general, all of these symptoms do not exist simultaneously on the same infected tree (Sagaram et al. 2009). Taken together, HLB symptoms involve chlorosis or discoloration due to the degradation of photosynthetic pigments such as chlorophylls and carotenoids.
Recently, our recognition of physiological events associated with ' $C a$. L. asiaticus' infection or $D$. citri infestation has been greatly improved. However, the mechanisms of HLB symptom development are still unexplored. In order to understand the mechanism of chlorosis or discoloration development, we investigated the chlorophyll and carotenoid contents in 'Valencia' sweet orange (Citrus sinensis (L.) Osbeck) leaves after infection with ' $C a$. L. asiaticus' or infestation with its vector, D. citri. Herein, we tested the hypothesis that both ' $C a$. L. asiaticus' and $D$. citri cause changes in leaf pigments but through two different mechanisms.

\section{RESULTS}

Using high-performance liquid chromatography (HPLC) to study citrus leaf pigments, we were able to detect and quantify 15 different pigments belonging to three groups (carotenes, xanthophylls, and chlorophylls) (Fig. 1; Table 1). Four pigments were detected from the chlorophyll group (chlorophyll $a$, chlorophyll $b$, pheophytin $a$, and chlorophyllide $a$ ). Eight pigments were identified as xanthophylls (neoxanthin, transviolaxanthin, cis-violaxanthin, zeaxanthin, lutein, isolutein, $\alpha$-cryptoxanthin, and $\beta$-cryptoxanthin). Finally, cis- $\beta$-carotene, $\alpha$-carotene, and $\beta$-carotene were detected from the carotenes group.

\section{' $C a$. L. asiaticus' and $D$. citri alter citrus leaf pigments content.}

The total pigment content was significantly reduced by ' $\mathrm{Ca}$. L . asiaticus' infection $\left(518.61 \pm 75.28 \mu \mathrm{g} \mathrm{g}^{-1}\right.$ fresh weight $\left.[\mathrm{FW}]\right)$ followed by $D$. citri infestation $\left(1,022.75 \pm 145.55 \mu \mathrm{g} \mathrm{g}^{-1} \mathrm{FW}\right)$ compared with control plants $\left(1,294.66 \pm 158.78 \mu \mathrm{g} \mathrm{g}^{-1} \mathrm{FW}\right)$. Interestingly, this effect was compromised in the double-attacked plants $\left(626.08 \pm 109.55 \mu \mathrm{g} \mathrm{g}^{-1} \mathrm{FW}\right)$ (Fig. 2A). Additionally, the total chlorophyll, xanthophyll, and carotene contents as groups were significantly decreased in ' $\mathrm{Ca}$. L. asiaticus'-infected plants $\left(111.97 \pm 24.78,331.47 \pm 64.76\right.$, and $75.16 \pm 25.77 \mu \mathrm{g} \mathrm{g}^{-1} \mathrm{FW}$, respectively), followed by $D$. citri-infested plants $(514.22 \pm$ $92.63,358.35 \pm 46.18$, and $150.19 \pm 40.51 \mu \mathrm{g} \mathrm{g}{ }^{-1} \mathrm{FW}$, respectively) compared with the control (680.64 \pm 135.83 , $330.58 \pm 29.99$, and $283.44 \pm 57.00 \mu \mathrm{g} \mathrm{g}^{-1} \mathrm{FW}$, respectively). The total chlorophyll, xanthophyll, and carotene contents were compromised in double-attacked plants $(165.21 \pm 35.86,345.63 \pm$ 82.89, and $115.23 \pm 24.84 \mu \mathrm{g} \mathrm{g}^{-1} \mathrm{FW}$, respectively) (Fig. 2B).

The percentages of total chlorophylls, xanthophylls, and carotenes were similar in both ' $\mathrm{Ca}$. L. asiaticus'-positive and double-attacked plants and slightly different from D. citriinfested and control plants (Fig. 2C and D). Although chlorophylls were the most abundant group in control (49\%) and D. citri-infested $(50 \%)$ plants, chlorophylls were lower in ' $C a$. L. asiaticus'-positive and double-attacked plants (27 and $26 \%$, respectively). The xanthophyll group composes the majority of total leaf pigments $(55 \%)$ in ' $\mathrm{Ca}$. L. asiaticus'positive and double-attacked plants (Fig. 2C). These data suggest that infestation with $D$. citri does not change the pigment percentages whereas infection by ' $\mathrm{Ca}$. L. asiaticus' was responsible for reduction of chlorophyll and increase in xanthophyll percentages. Total carotene percentage was unaffected by either psyllid infestation or ' $\mathrm{Ca}$. L. asiaticus' infection.

\section{Infection with ' $\mathrm{Ca}$. L. asiaticus' increases zeaxanthin and decreases other pigments.}

The pigment profiles of ' $\mathrm{Ca}$. L. asiaticus'-infected and doubleattacked plants were more affected than $D$. citri-infested plants compared with control (Fig. 3A, B, and C). All chlorophyll compounds were reduced significantly within the profile of ' $\mathrm{Ca}$. L. asiaticus'-infected and double-attacked plants. The highest 
reduction was found in chlorophyll $a$ content in ' $\mathrm{Ca}$. L. asiaticus'-infected leaves $\left(21.65 \pm 8.30 \mu \mathrm{g} \mathrm{g}^{-1} \mathrm{FW}\right)$ followed by double-attacked plants $\left(21.85 \pm 9.87 \mu \mathrm{g} \mathrm{g}^{-1} \mathrm{FW}\right)$ compared with control $\left(379.25 \pm 97.06 \mu \mathrm{g} \mathrm{g}^{-1} \mathrm{FW}\right)$ (Fig. 3A). In the xanthophyll group, ' $C a$. L. asiaticus'-infected plants had the lowest concentrations of all detected xanthophylls followed by the double-attacked plants, except for zeaxanthin (Fig. 3B). No significant differences were found in $\beta$-cryptoxanthin among all studied treatments and the control. Zeaxanthin was significantly induced at higher levels in double-attacked leaves $\left(104.80 \pm 52.21 \mathrm{\mu g} \mathrm{g}^{-1} \mathrm{FW}\right)$ and ' $\mathrm{Ca}$. L. asiaticus'-infected leaves $\left(91.07 \pm 62.51 \mu \mathrm{g} \mathrm{g}^{-1} \mathrm{FW}\right)$ compared with the control $\left(34.79 \pm 15.96 \mu \mathrm{g} \mathrm{g}^{-1} \mathrm{FW}\right)$. The concentration of zeaxanthin in D. citri-infested leaves $\left(55.85 \pm 29.68 \mu \mathrm{g} \mathrm{g}^{-1} \mathrm{FW}\right)$ was not significantly affected compared with control plants (Fig. 3B).
All detected carotenes, including cis- $\beta$-carotene, $\alpha$-carotene, and $\beta$-carotene, were significantly reduced after ' $\mathrm{Ca}$. L. asiaticus' infection $\left(2.29 \pm 0.95,61.12 \pm 21.27\right.$, and $11.75 \pm 4.95 \mu \mathrm{g} \mathrm{g}^{-1} \mathrm{FW}$, respectively) compared with the control $(5.68 \pm 0.65,245.43 \pm$ 49.77, and $32.33 \pm 7.51 \mu \mathrm{g} \mathrm{g}^{-1} \mathrm{FW}$, respectively). However, levels of cis- $\beta$-carotene were similar in the three treatments, whereas $\alpha$ - and $\beta$-carotene showed differences between treatments. (Fig. 3C).

\section{Infestation with $D$. citri increases chlorophyllide $a$ and decreases some other pigments.}

Among the four detected chlorophyll compounds in the $D$. citri-infested plants, only chlorophyll $a$ and chlorophyll $b$ were decreased $\left(178.16 \pm 62.01\right.$ and $115.41 \pm 23.49 \mu \mathrm{g} \mathrm{g}^{-1} \mathrm{FW}$, respectively) compared with the control $(379.25 \pm 97.06$ and

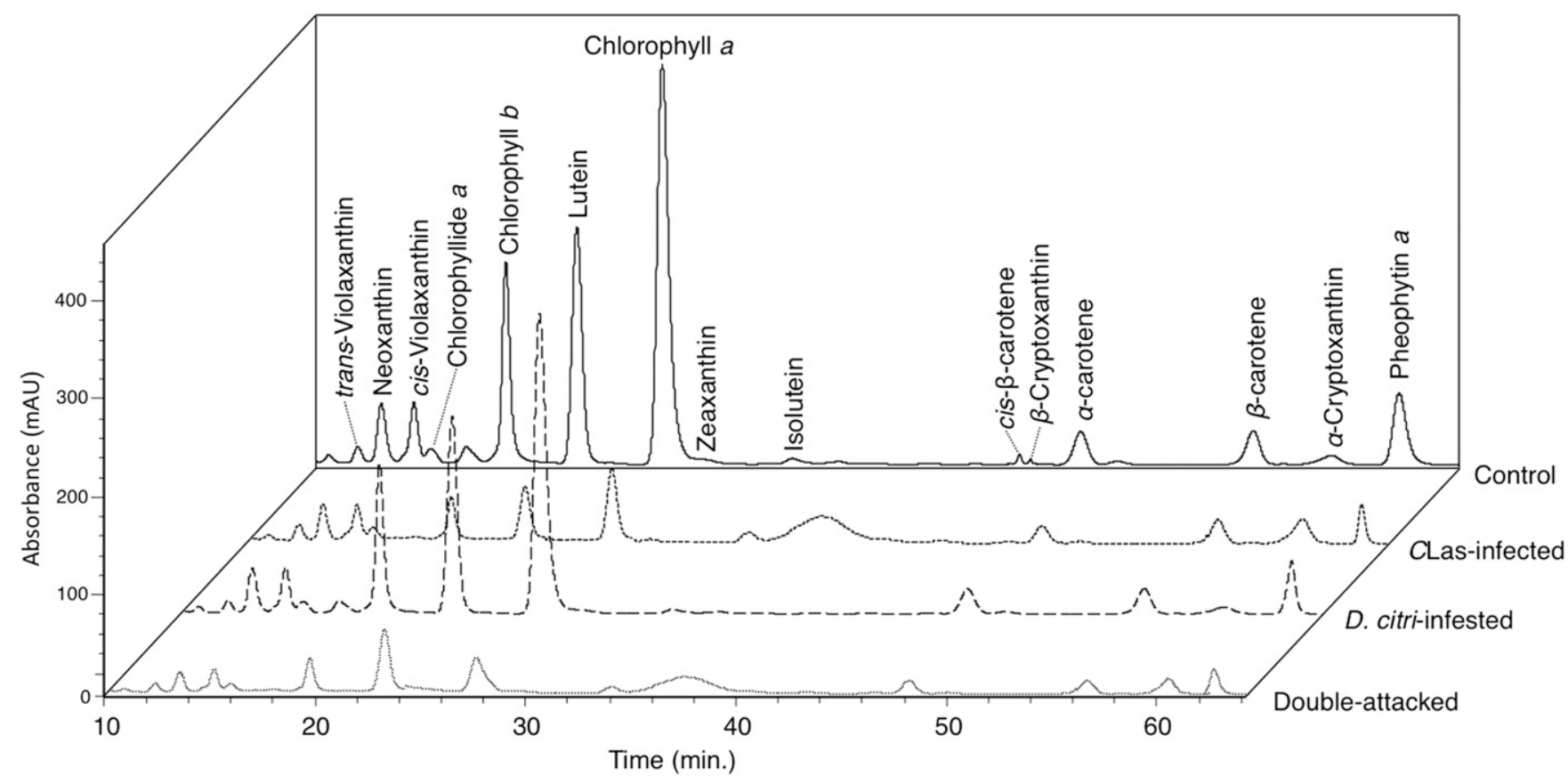

Fig. 1. Representative high-performance liquid chromatography chromatogram of Valencia sweet orange (Citrus sinensis) leaf pigments after infection with 'Candidatus Liberibacter asiaticus' or herbivory with Diaphorina citri. $\mathrm{mAU}=$ milli-absorbance units at $486 \mathrm{~nm}$.

Table 1. Chromatographic and spectral characteristics of different investigated pigments in citrus leaves using high-performance liquid chromatography

\begin{tabular}{|c|c|c|c|c|c|c|c|c|c|c|}
\hline \multirow[b]{3}{*}{ Plant pigments } & \multirow[b]{3}{*}{$\mathbf{R T}(\min )^{\mathrm{x}}$} & \multicolumn{8}{|c|}{$\lambda_{\max }(\mathrm{nm})$ At peaks I to IV } & \multirow[b]{3}{*}{ Reference } \\
\hline & & \multicolumn{4}{|c|}{ Observed } & \multicolumn{4}{|c|}{ Literature } & \\
\hline & & $\mathbf{I}$ & II & III & IV & $\mathbf{I}$ & II & III & IV & \\
\hline 1, trans-Violaxanthin $\mathrm{y}$ & 12.02 & 415 & 439 & 468 & $\ldots$ & 416 & 439 & 469 & $\ldots$ & Wei et al. 2014b \\
\hline 2, Neoxanthin ${ }^{y}$ & 13.10 & 413 & 438 & 468 & $\ldots$ & 412 & 434 & 463 & $\ldots$ & Rodrigo et al. 2004 \\
\hline 3, cis-Violaxanthin ${ }^{\mathrm{y}}$ & 14.70 & 327 & 412 & 436 & 464 & 325 & 411 & 434 & 463 & Rodrigo et al. 2004 \\
\hline 4, Chlorophyllide $a$ & 15.04 & 413 & 431 & 461 & $\ldots$ & 412 & 431 & 460 & 662 & Milenković et al. 2012 \\
\hline 5, Chlorophyll $b^{\mathrm{z}}$ & 19.07 & 439 & 469 & $\ldots$ & $\ldots$ & 438 & 468 & & $\ldots$ & Edelenbos et al. 2001 \\
\hline 6, Lutein ${ }^{\mathrm{z}}$ & 22.50 & 421 & 444 & 472 & $\ldots$ & 420 & 444 & 472 & & Wei et al. $2014 \mathrm{~b}$ \\
\hline 7, Chlorophyll $a^{z}$ & 27.01 & 339 & 386 & 416 & 432 & 338 & 386 & 414 & 432 & Edelenbos et al. 2001 \\
\hline 8, Zeaxanthin ${ }^{\mathrm{z}}$ & 27.83 & 424 & 449 & 476 & $\ldots$ & 424 & 450 & 477 & $\ldots$ & Wei et al. 2014b \\
\hline 9, Isoluiein ${ }^{\mathrm{y}}$ & 32.96 & 416 & 440 & 468 & $\ldots$ & 416 & 440 & 468 & $\ldots$ & Wei et al. $2014 \mathrm{~b}$ \\
\hline 10, cis- $\beta-$-Carotene ${ }^{\mathrm{y}}$ & 43.91 & 340 & 421 & 445 & 472 & 340 & 422 & 446 & 473 & Rodrigo et al. 2004 \\
\hline $11, \beta$-Cryptoxanthin $\mathrm{y}$ & 44.76 & 425 & 450 & 477 & $\ldots$ & 426 & 451 & 478 & $\ldots$ & Wei et al. 2014b \\
\hline $12, \alpha$-Carotene ${ }^{z}$ & 46.46 & 422 & 445 & 473 & $\ldots$ & 421 & 446 & 473 & $\ldots$ & Wei et al. 2014b \\
\hline $13, \beta$-Carotene ${ }^{\mathrm{z}}$ & 54.68 & 427 & 451 & 475 & $\ldots$ & 426 & 451 & 473 & $\ldots$ & Rodrigo et al. 2004 \\
\hline $14, \alpha$-Cryptoxanthin $\mathrm{y}$ & 58.21 & 418 & 440 & 476 & $\ldots$ & 419 & 445 & 472 & & Rodrigo et al. 2004 \\
\hline 15, Pheophytin $a^{\mathrm{y}}$ & 61.75 & 328 & 410 & 506 & 537 & 328 & 410 & 505 & 535 & Edelenbos et al. 2001 \\
\hline
\end{tabular}

x Retention time.

y Tentative identification by comparison with data available in literature.

${ }^{\mathrm{z}}$ Identified using authentic standards. 
$139.34 \pm 24.37 \mu \mathrm{g} \mathrm{g}^{-1} \mathrm{FW}$, respectively) (Fig. 3A). Furthermore, chlorophyllide $a$ was dramatically increased in $D$. citri-infested plants $\left(127.46 \pm 52.77 \mu \mathrm{g} \mathrm{g}^{-1} \mathrm{FW}\right)$ compared with the control $\left(47.13 \pm 15.10 \mu \mathrm{g} \mathrm{g}^{-1} \mathrm{FW}\right)$. No significant differences were found in pheophytin $a$ between them (Fig. 3A). Likewise, among the eight detected xanthophylls, four compounds were significantly decreased in $D$. citri-infested plants, including $\alpha$-cryptoxanthin $\left(2.97 \pm 2.09 \mu \mathrm{g} \mathrm{g}^{-1} \mathrm{FW}\right)$, trans-violaxanthin $(18.58 \pm 3.43 \mu \mathrm{g}$ $\left.\mathrm{g}^{-1} \mathrm{FW}\right)$, neoxanthin $\left(45.99 \pm 10.05 \mu \mathrm{g} \mathrm{g}^{-1} \mathrm{FW}\right)$, and lutein $\left(154.56 \pm 31.77 \mu \mathrm{g} \mathrm{g}^{-1} \mathrm{FW}\right)$ compared with the control (4.82 \pm $1.70,23.05 \pm 9.57,62.18 \pm 18.47$, and $211.89 \pm 25.19 \mu \mathrm{g} \mathrm{g}^{-1}$ FW, respectively). Meanwhile, $D$. citri infestation did not affect levels of other xanthophylls (Fig. 3B). In the carotene group, all compounds, including cis- $\beta$-carotene, $\alpha$-carotene, and $\beta$-carotene, were reduced in $D$. citri-infested plants $(3.48 \pm$ $1.33,121.05 \pm 30.39$, and $25.65 \pm 11.18{\mu g^{-1}}^{-1 W}$, respectively) compared with the control $(5.68 \pm 0.65,245.43 \pm 49.77$, and $32.33 \pm 7.51 \mu \mathrm{g} \mathrm{g}^{-1} \mathrm{FW}$, respectively) (Fig. 3C).

Principal components analysis (PCA) and hierarchical cluster analysis (HCA) analyses revealed the differences among treatments.

The score plot obtained from PCA showed a clear separation among ' $C a$. L. asiaticus'-infected and double-attacked (as overlapping groups), control, and D. citri-infested plants with respect to principal component (PC)1 (53.4\%) and PC2 (12.3\%) (Fig. 4A). The loading plot showed that zeaxanthin was positively correlated with ' $\mathrm{Ca}$. L. asiaticus' infection and double-attacked treatments, whereas the rest of the pigments were positively correlated with control and D. citri-infested plants (Fig. 4B). In addition, the two-way HCA and heat map were performed using the individual compounds. The citrus pigment profile in the leaves from ' $\mathrm{Ca}$. L. asiaticus'-infected plants was more similar to the double-attacked plants (approximately 85\% similarity) than D. citri-infested (approximately $70 \%$ similarity) and healthy (less than $55 \%$ similarity) plants. For the cluster between compounds, chlorophylls, except chlorophyllide $a$, were very close to each other (more than $96 \%$ similarity) and carotenes were clustered together also (less than $80 \%$ similarity) (Fig. 4C). Chlorophyllide $a$ (less than $56 \%$ similarity) and zeaxanthin (less than $48 \%$ similarity) were clustered separately from their groups in the end of the right side of the dendrogram. Additionally, the presented heat map supports the previous findings that the pigment profile from ' $\mathrm{Ca}$. L. asiaticus'-infected plants is closer to doubleattacked plants than D. citri-infested or control plants (Fig. 4C).

Relationships among different citrus leaf pigment groups.

The three-dimensional (3D) surface plots were obtained using the whole data matrix to understand the relationships between chlorophylls, xanthophylls, and carotenes in citrus leaves
A

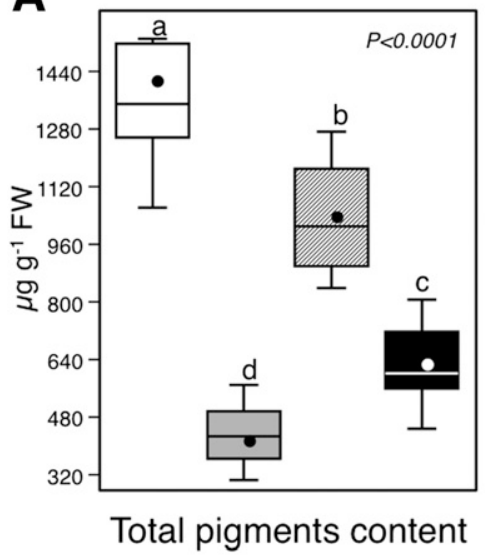

B

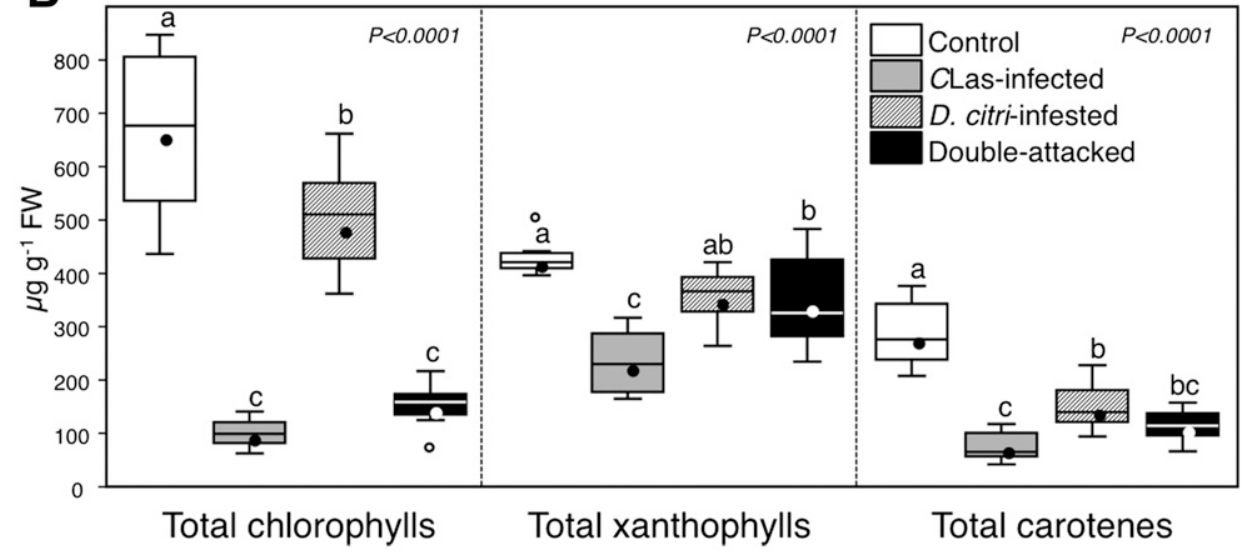

\section{C}

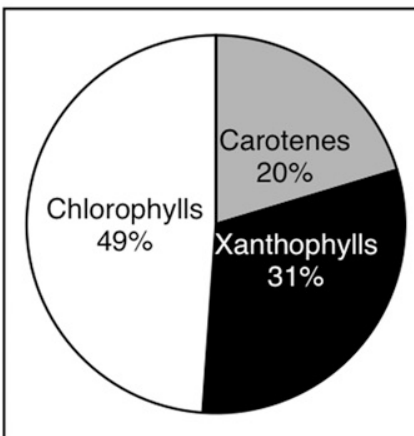

Control

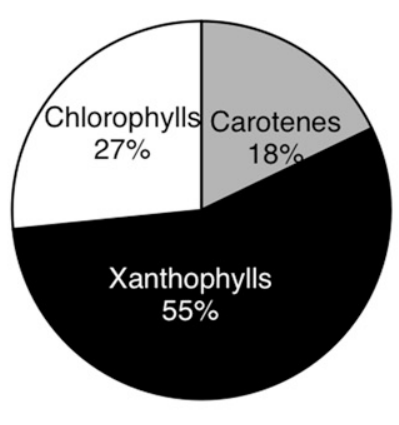

CLas-infected

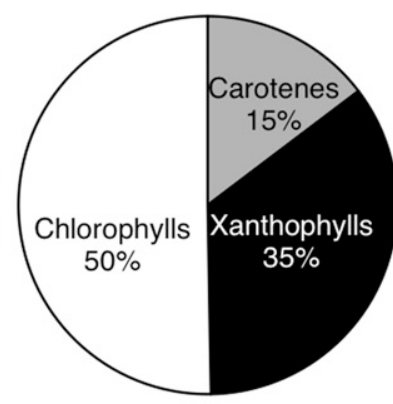

D. citri-infested

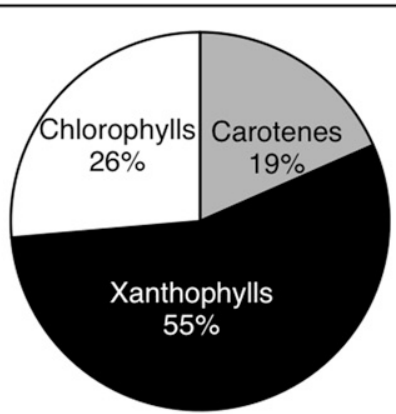

Double-attacked

Fig. 2. Concentrations of $\mathbf{A}$, total leaf pigments; $\mathbf{B}$, pigment group concentrations; and $\mathbf{C}$, percentage composition for pigment groups of Valencia sweet orange (Citrus sinensis) after infection with 'Candidatus Liberibacter asiaticus' (CLas) or the herbivory with Diaphorina citri using high-performance liquid chromatography $(n=10)$. The total leaf pigment content was calculated as a total of chlorophyll, xanthophyll, and carotene groups; chlorophyll group contains chlorophyll $a$, chlorophyll $b$, pheophytin $a$, and chlorophyllide $a$; xanthophyll group contains neoxanthin, trans-violaxanthin, $c i s$-violaxanthin, zeaxanthin, lutein, isolutein, $\alpha$-cryptoxanthin, and $\beta$-cryptoxanthin; and carotene group contains cis- $\beta$-carotene, $\alpha$-carotene, and $\beta$-carotene. Horizontal thick lines indicate the medians, black and white dots indicate the means, boxes show the interquartile ranges including 25 to $75 \%$ of the values, and whiskers reflect the highest and the lowest value of data. Different letters indicate statistically significant differences among treatments $(P<0.05)$ and "ns" signifies no significant differences among treatments. 
in the studied four conditions (Fig. 5A to L). Overall, the relationships among these groups are complex. The effect of xanthophylls and carotenes on chlorophyll content was obtained and presented in Figure 5A to D. The total net profits (TNP) of chlorophyll content in ' $\mathrm{Ca}$. L. asiaticus'-infected (Fig. 5B) and D. citri-infested (Fig. 5C) plants appeared to be higher in highcarotene conditions. Additionally, the TNP of double-attacked plants showed compromises for the effect of ' $\mathrm{Ca}$. L. asiaticus'

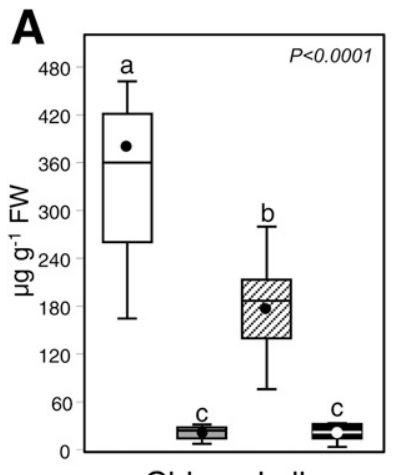

Chlorophyll a
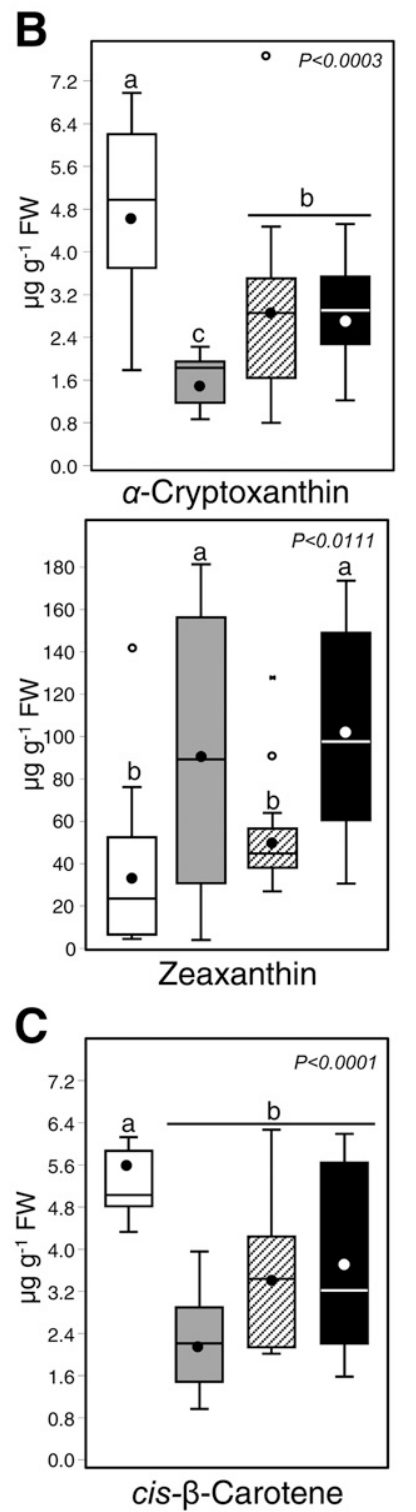
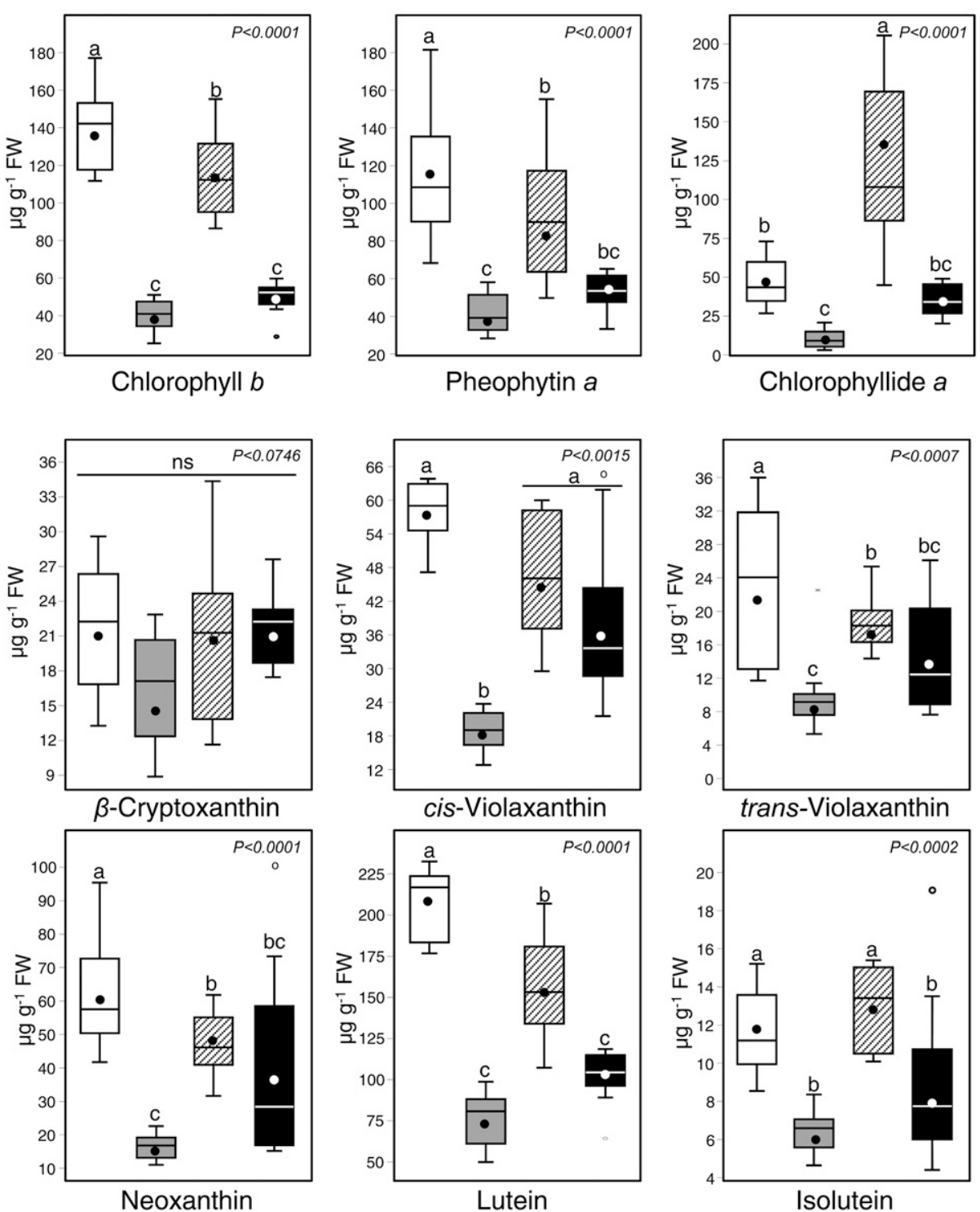

Lutein

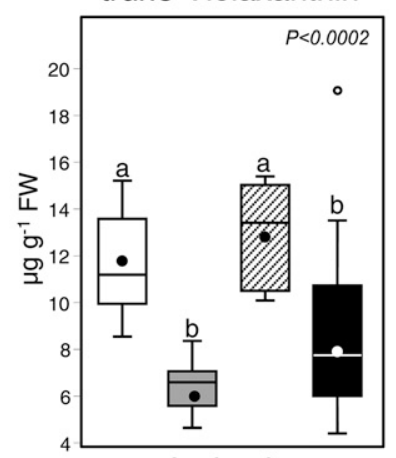

Isolutein
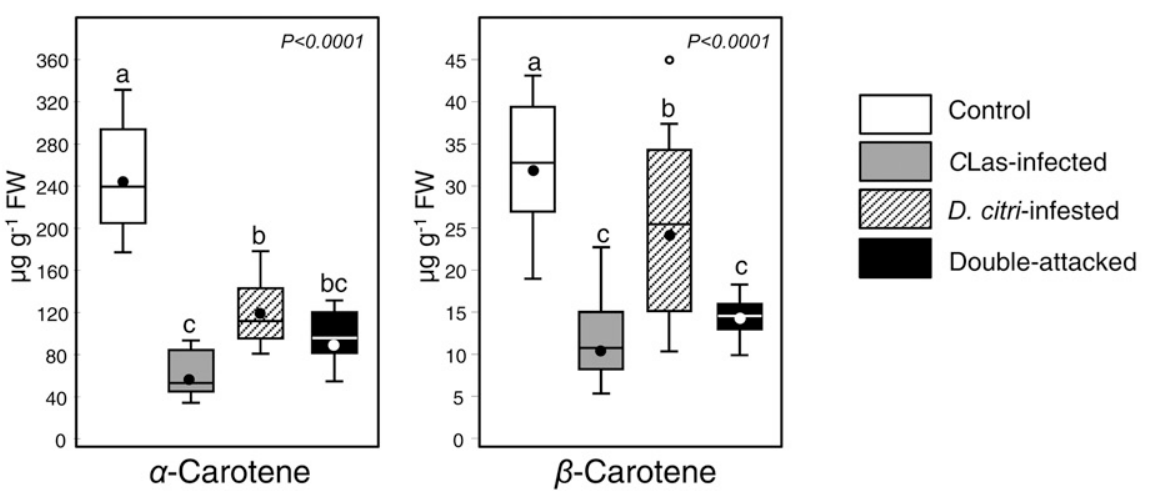

Fig. 3. Concentrations of individual leaf pigments detected in Valencia sweet orange (Citrus sinensis) leaves after infection with 'Candidatus Liberibacter asiaticus' (CLas) or herbivory with Diaphorina citri using high-performance liquid chromatography $(n=10)$. A, Chlorophyll; B, xanthophyll; and C, carotene groups. Horizontal thick lines indicate the medians, black and white dots indicate the means, boxes show the interquartile ranges including 25 to $75 \%$ of the values, and whiskers reflect the highest and the lowest value of data. Different letters indicate statistically significant differences among treatments $(P<0.05)$ and "ns" signifies no significant differences among treatments. 
infection and D. citri herbivory, without any effect of xanthophyll and carotene content on chlorophyll TNP (Fig. 5D). Furthermore, the effect of xanthophyll and chlorophyll on carotene content is presented in Figure 5E to H. Generally, the TNP of carotenes was similar in all treatments compared with control plants, which had a sharp peak (Fig. 5E). The carotene TNP in ' $C a$. L. asiaticus'-infected (Fig. 5F) and D. citri-infested (Fig. 5G) plants were higher in high-xanthophyll and high-chlorophyll conditions. The effect of carotene and chlorophyll content on xanthophyll content is presented in Figure 5I to L. The xanthophyll TNP of ' $C a$. L. asiaticus'-infected, D. citri-infested, and double-attacked plants was very different compared with the control, which had a sharp peak in low-chlorophyll and highcarotene conditions, with clearly flat plateaus (Fig. 5I). The xanthophyll TNP in ' $\mathrm{Ca}$. L. asiaticus'-infected (Fig. 5J) and D. citri-infested (Fig. 5K) plants appeared to be higher in highcarotene and high-chlorophyll conditions (Fig. 5J).

\section{' $\mathrm{Ca}$. L. asiaticus' infection induces the accumulation} of abscisic acid (ABA) and starch.

ABA, starch, and sucrose levels were determined and presented in Figure 6A to $\mathrm{C}$ to explore the effect of citrus leaf
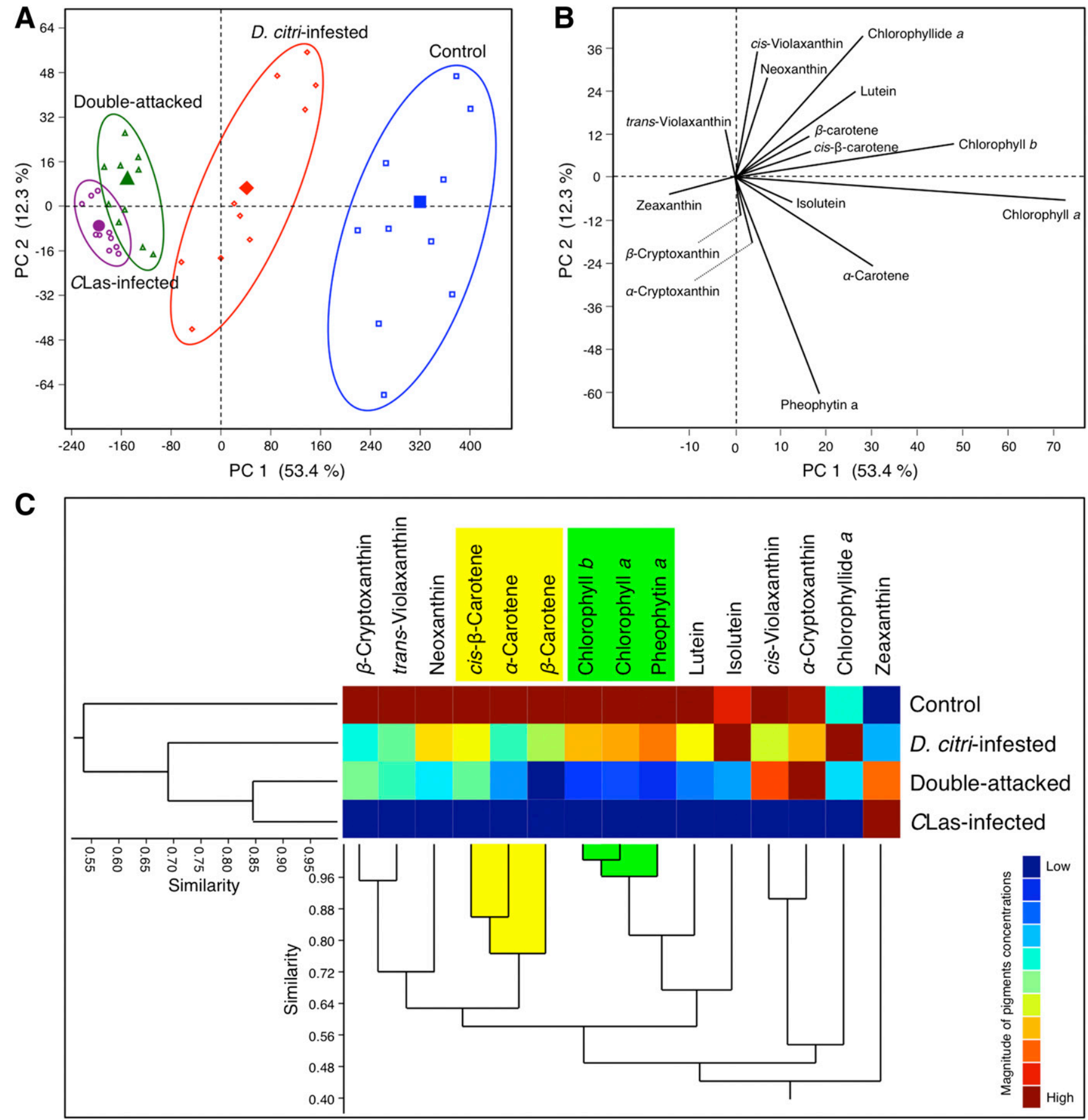

Fig. 4. Principal component analysis (PCA) of different leaf pigments detected and quantified using high-performance liquid chromatography in Valencia sweet orange (Citrus sinensis) after infection with 'Candidatus Liberibacter asiaticus' (CLas) or herbivory with Diaphorina citri $(n=10)$. A, PCA-scatter plot; B, PCA-loading plot; and C, two-way hierarchical cluster analysis dendrograms. 
pigment deficiency on other metabolites. ' $\mathrm{Ca}$. L. asiaticus' infection induced the accumulation of ABA $\left(1,564.3 \pm 742.7 \mathrm{ng} \mathrm{g}^{-1}\right.$ FW) and starch (171.53 $\left.\pm 18.92 \mathrm{mg} \mathrm{g}^{-1} \mathrm{FW}\right)$ but it did not affect the sucrose level $\left(69.81 \pm 4.66 \mathrm{mg} \mathrm{g}^{-1} \mathrm{FW}\right)$ compared with the control $\left(121.0 \pm 44.4 \mathrm{ng} \mathrm{g}^{-1} \mathrm{FW}, 14.68 \pm 0.75 \mathrm{mg} \mathrm{g}^{-1} \mathrm{FW}\right.$, and $69.07 \pm 6.73 \mathrm{mg} \mathrm{g}^{-1} \mathrm{FW}$, respectively). On the other hand, although $D$. citri infestation did not alter the ABA (403.8 \pm $\left.212.4 \mathrm{ng} \mathrm{g}^{-1} \mathrm{FW}\right)$ or starch $\left(29.17 \pm 5.91 \mathrm{mg} \mathrm{g}^{-1} \mathrm{FW}\right)$ levels,
A
온
잉

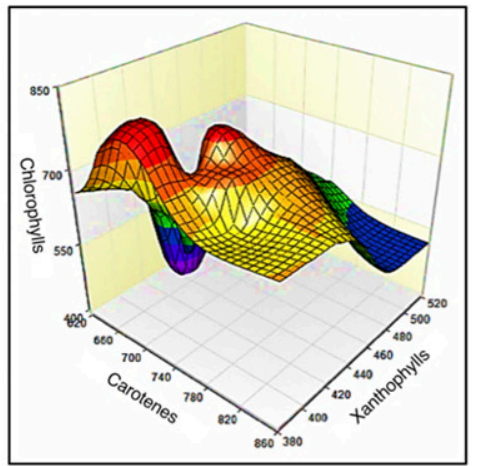

B

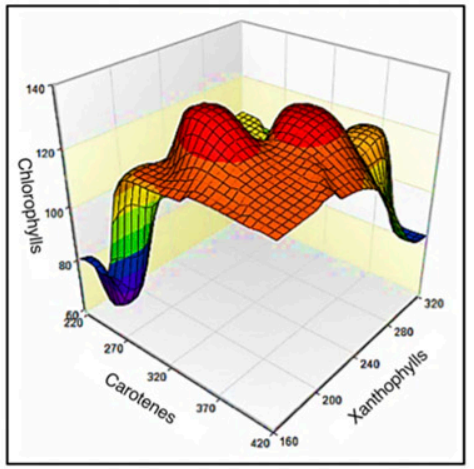

C

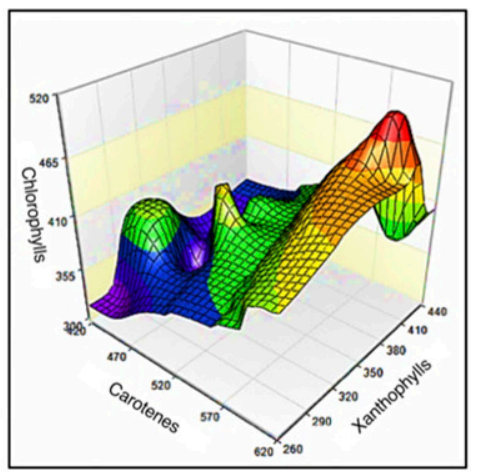

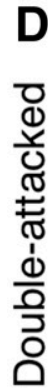

$\mathbf{E}$

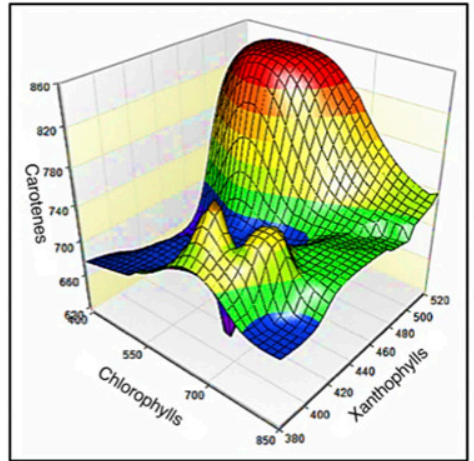

$\mathbf{F}$

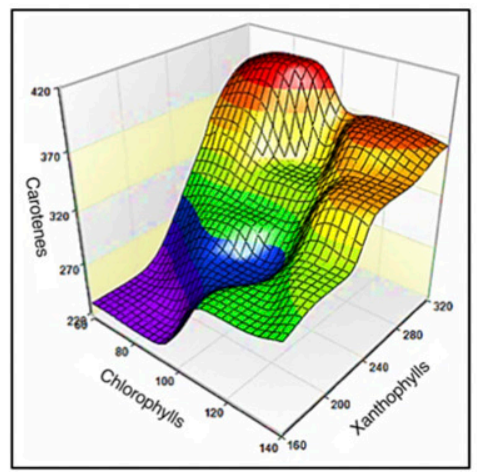

G

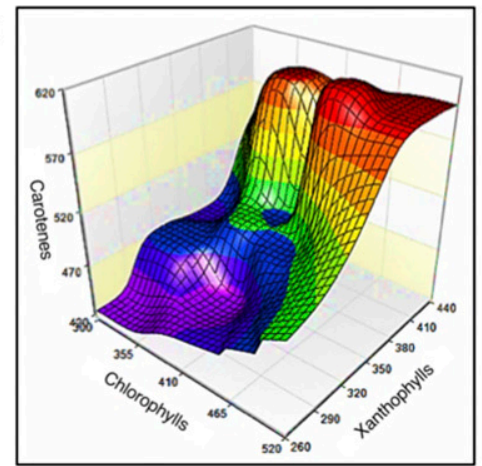

H

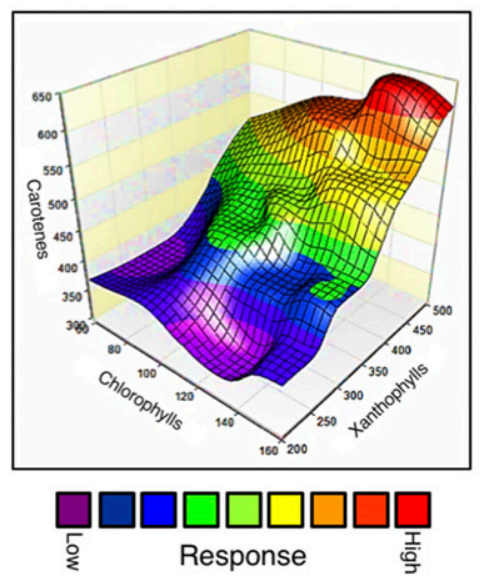

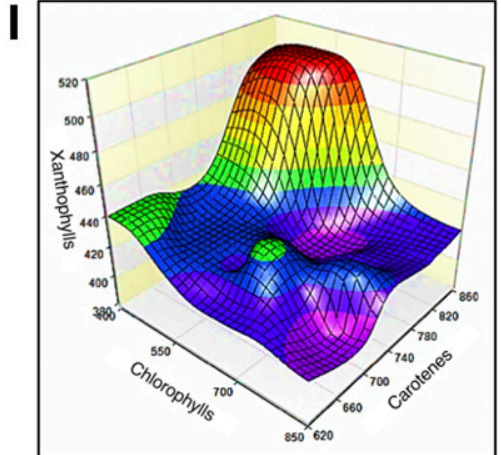

$\mathbf{J}$

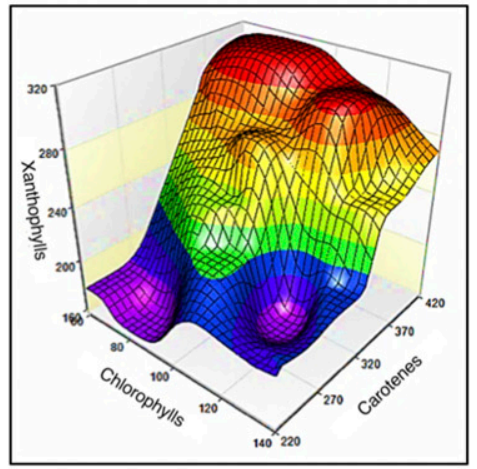

$\mathbf{K}$

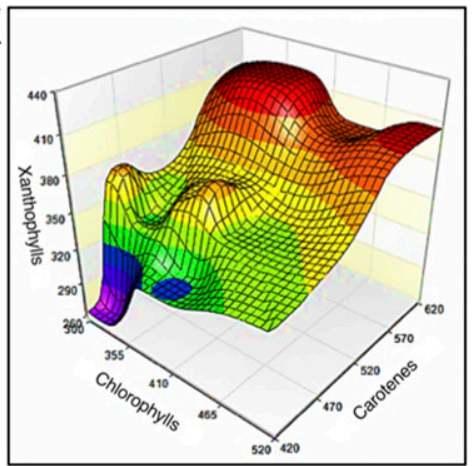

$\mathbf{L}$

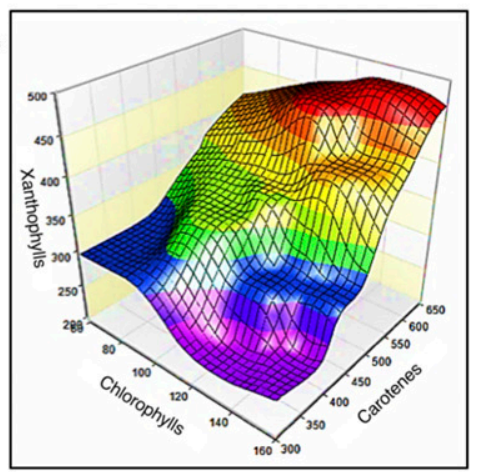

Fig. 5. Three-dimensional surface plots of leaf pigments groups detected using high-performance liquid chromatography in Valencia sweet orange (Citrus sinensis) leaves after infection with 'Candidatus Liberibacter asiaticus' (CLas) or herbivory with Diaphorina citri. A, B, C, and D, Reciprocal interaction of carotenes and xanthophylls on chlorophyll content; $\mathbf{E}, \mathbf{F}, \mathbf{G}$, and $\mathbf{H}$, reciprocal interaction of chlorophylls and xanthophylls on carotene content; and I, J, K, and $\mathbf{L}$, reciprocal interaction of carotenes and chlorophylls on xanthophyll content in different treatments. 
it reduced the sucrose content $\left(40.61 \pm 3.94 \mathrm{mg} \mathrm{g}^{-1} \mathrm{FW}\right)$ compared with the control. The effects of ' $\mathrm{Ca}$. L. asiaticus' and D. citri were compromised in the double-attacked plants (Fig. 6).

\section{' $\mathrm{Ca}$. L. asiaticus' and $\mathrm{D}$. citri alter the expression of genes implicated in carotenoid and chlorophyll biosynthesis pathways.}

The transcription levels of 46 genes involved in biosynthetic pathways of carotenoids (29 genes) and chlorophylls (17 genes) were investigated in Valencia sweet orange leaves (Fig. 7). Gene expression data were normalized using four reference genes: elongation factor 1- $\alpha(E F 1)$, F-box/kelch-repeat protein $(F-b o x)$, glyceraldehyde-3-phosphate dehydrogenase GAPC1, cytosolic ( $G A P C 1$, also known as $G A P D H)$, and SAND family protein $(S A N D)$. Previous work showed the high stability of these genes for transcript normalization in different citrus organs under biotic stress (Mafra et al. 2012; Wei et al. 2014a,b). The normalizing expression levels using the four reference genes were very similar (data not shown). The full lists of expressed genes, names, accession numbers, and primers are available in Supplementary Tables S1 and S2. The heat map presented in Figure 7B shows that 15 carotenoid biosynthetic genes were downregulated and 14 genes were upregulated, including carotenoid hydroxylase $\beta$-ring (CitCHYbs), zeaxanthin epoxidase (CitZEPs), violaxanthin deepoxidase (CitVDE), capsanthin/capsorubin synthase (CitCCS), neoxanthin synthase (CitNSY), 9-cis-epoxycarotenoid dioxygenase 3 (CitNCED), short chain alcohol dehydrogenase (Cit$A B A 2$ ), and abscisic aldehyde oxidase (CitAAO3), after ' $\mathrm{Ca}$. L. asiaticus' infection or D. citri infestation. Furthermore, the hierarchical clustering dendrogram (HCD) among treatments (Fig. 7B) shows that ' $\mathrm{Ca}$. L. asiaticus'-infected plants were closer to double-attacked (more than $90 \%$ similarity) than to D. citriinfested (less than 64\% similarity) and control (less than $45 \%$ similarity) plants. HCD among the studied genes represents high similarity in the expression of CitCHYbs and CitZEPs, which are clustered separately in two clusters within the same group (more than $70 \%$ similarity). In addition, ABA-biosynthetic genes (CitNSY, CitNCED, CitABA2, and CitAAO3) shared similar patterns and clustered together (Fig. 7B). Likewise, all chlorophyll biosynthetic genes were downregulated, except for chlorophyllase (CitChlase, also known as $C L H$ ) and chlorophyll (ide) b reductase $($ CitCBR), including chlorophyll(ide) b reductase-non-yellow coloring 1 (CitNYCl) and chlorophyll(ide) b reductase -NYC1-like (CitNOL). CitChlase and CitCBR (CitNYCl and CitNOL) were highly expressed in D. citriinfested plants compared with the control (Fig. 7C). HCD among treatments indicates that, whereas ' $\mathrm{Ca}$. L. asiaticus'-infected plants were very similar to double-attacked plants (over $80 \%$ similarity), D. citri-infested plants clustered separately (approximately 64\% similarity). HCD among studied chlorophyll biosynthetic genes revealed two main clusters: the first cluster for CitCBR (more than $80 \%$ similarity) and the second cluster containing CitChlase genes (more than 70\% similarity) (Fig. 7C). Accordingly, the gene expression analysis supported our findings of HPLC and enzyme-linked immunosorbent assay (ELISA) analyses.

\section{DISCUSSION}

Our findings showed that ' $\mathrm{Ca}$. L. asiaticus' infection or D. citri infestation altered citrus leaf pigments dramatically, with a greater effect in ' $\mathrm{Ca}$. L. asiaticus'-infected trees. Of 15 detected pigments, 13 compounds were decreased in ' $\mathrm{Ca}$. L. asiaticus'-infected leaves and 9 pigments were reduced in D. citri-infested leaves. Many previous studies were carried out to examine the effect of pathogen infection or insect herbivory on plant pigment groups, especially carotenoids and chlorophylls (Blanchfield et al. 2005, 2007; Huang et al. 2013; Kumar and Sharma 2014). However, these studies were primarily focused on the effect of viral pathogens on leaf pigments. For example, a reduction in photosynthetic pigments (chlorophyll $a$, chlorophyll $b, \beta$-carotene, neoxanthin, violaxanthin, and lutein) was observed in potato plants (Solanum tuberosum) infected with Potato virus $Y^{\text {NTN }}$ (Milavec et al. 1999). In addition, Papaya ring spot virus-papaya strain infection caused a decrease in cellular pigments (chlorophyll $a$, chlorophyll $b$, and $\beta$-carotene) in papaya plants (Carica papaya) (Rahman et al. 2008). Tobacco mosaic virus infection resulted in reduction of chlorophyll $a$ and chlorophyll $b$ in several pepper varieties (Capsicum annuum L.) (Pazarlar et al. 2013). Similarly, bacterial pathogens alter the photosynthetic pigments in their

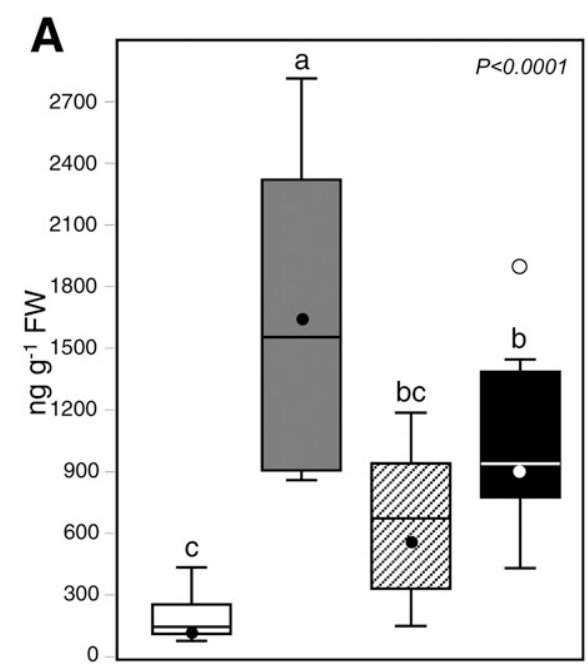

Abscisic acid

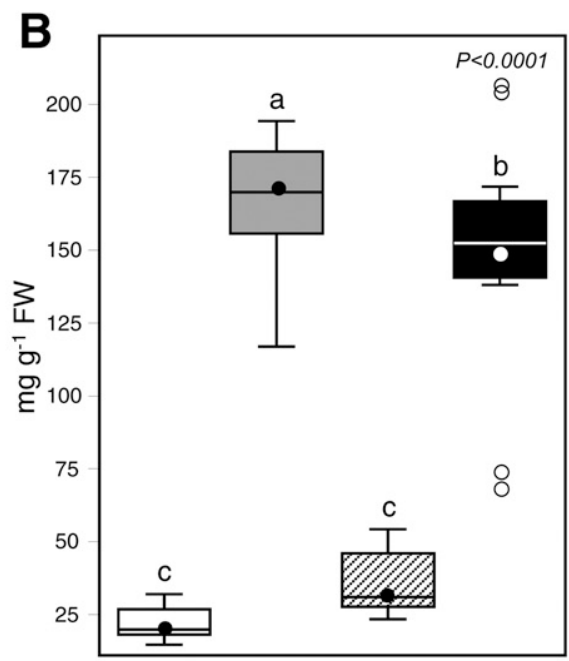

Starch

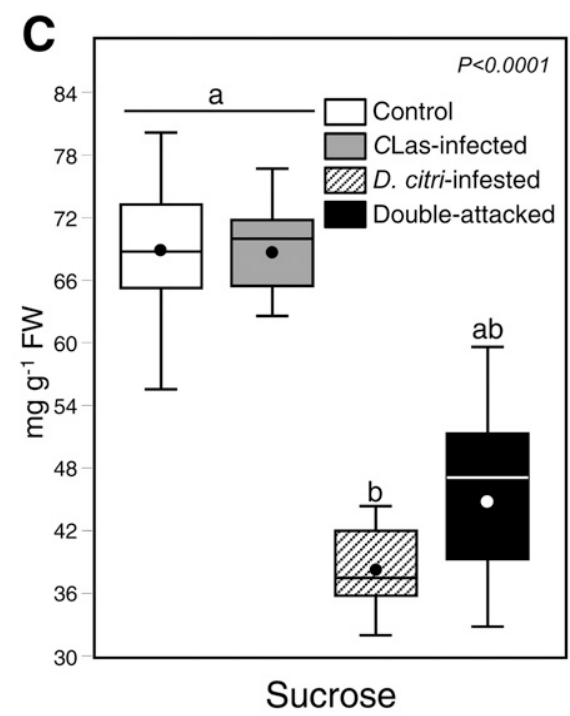

Fig. 6. A, Abscisic acid; B, starch; and C, sucrose content of Valencia sweet orange (Citrus sinensis) after the infection with 'Candidatus Liberibacter asiaticus' (CLas) or the infestation with Diaphorina citri $(n=10)$. Horizontal thick lines indicate the medians, black and white dots indicate the means, boxes show the interquartile ranges including 25 to $75 \%$ of the values, and whiskers reflect the highest and the lowest values of data. Different letters indicate statistically significantly differences among treatments $(P<0.05)$ and "ns" signifies no significant differences among treatments. 
hosts. Higher levels of total carotenoids and total chlorophylls were recorded in different healthy rice genotypes in comparison with those infected by Xanthomonas oryzae pv. oryzae, the causal agent of bacterial blight disease in rice (Kumar et al. 2013).
Additionally, changes in photochemical or nonphotochemical quenching parameters and chlorophyll fluorescence were found in citrus leaves after ' $\mathrm{Ca}$. L. asiaticus' infection (Sagaram et al. 2009).
A

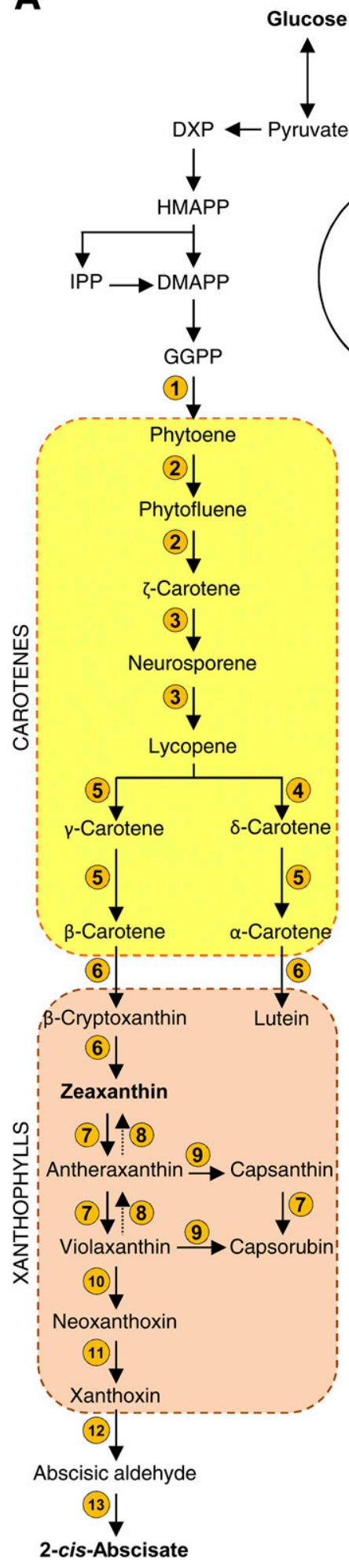

B

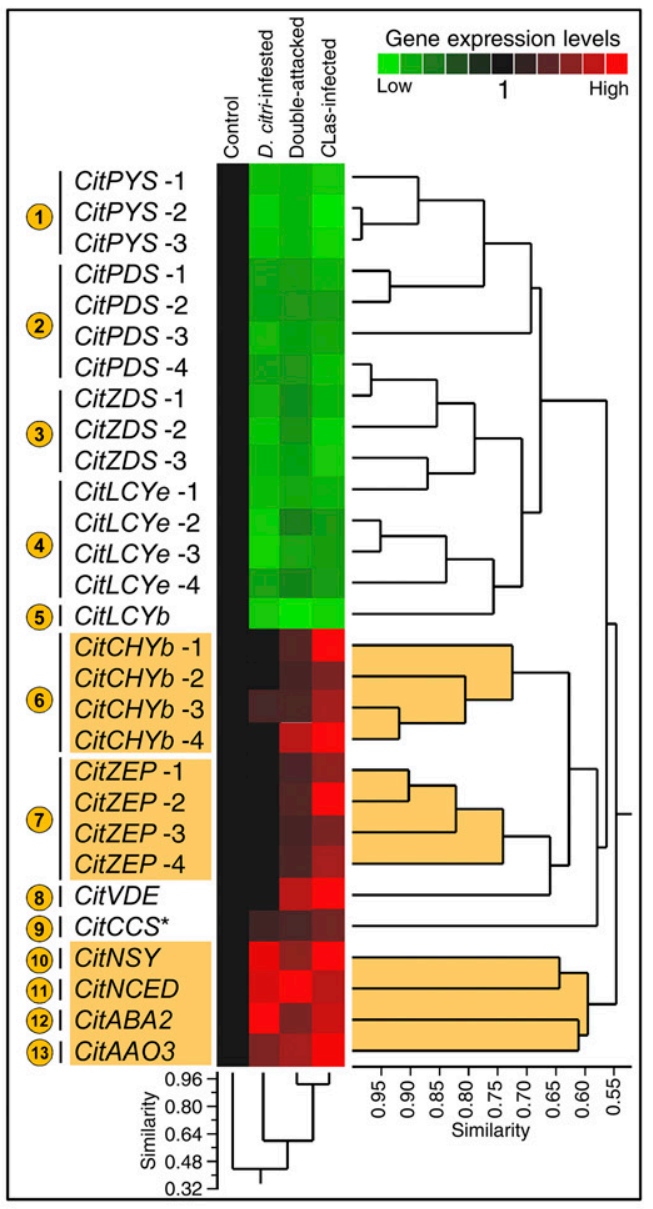

cycle $\alpha$-ketoglutarate

cycle $\alpha$-ketoglutarate
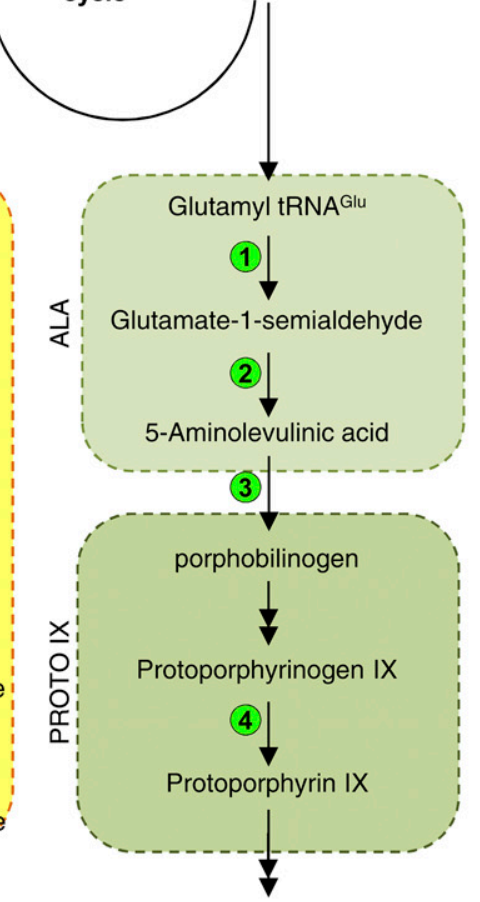

Divinyl protochlorophyllide

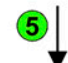

protochlorophyllide

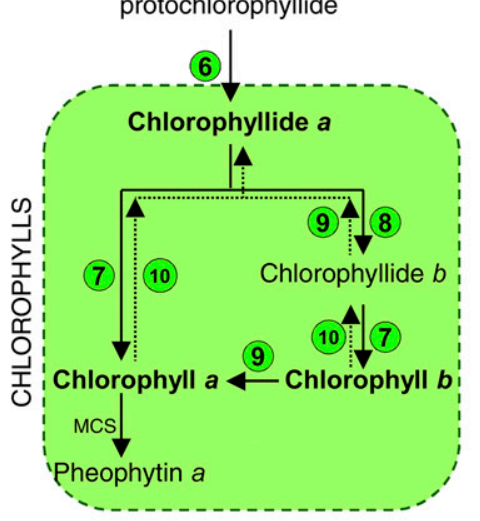

c

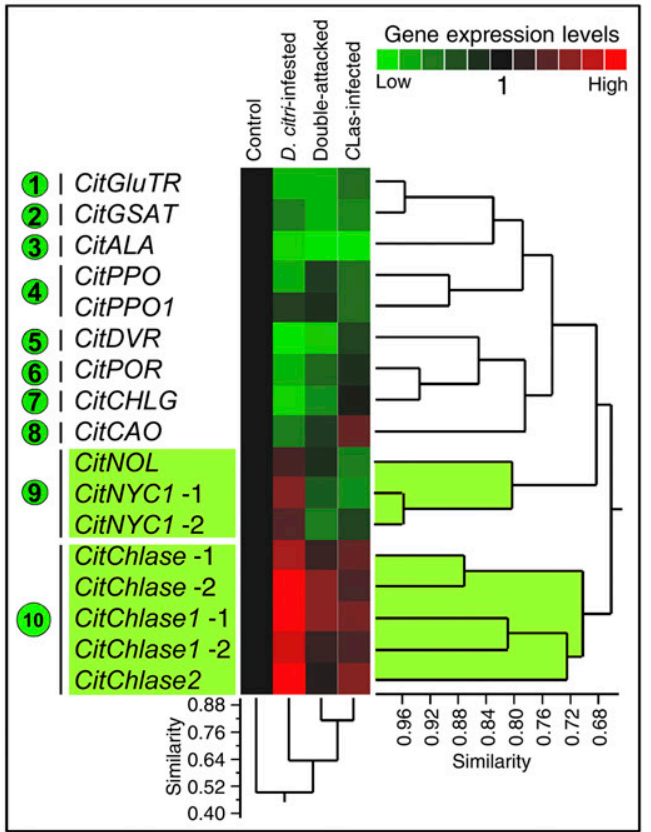

Fig. 7. A, Plant pigment biosynthesis pathways and heat map diagrams of differential biosynthetic gene expression patterns of $\mathbf{B}$, carotenoids and $\mathbf{C}$, chlorophylls detected in Valencia sweet orange (Citrus sinensis) leaves after infection with 'Candidatus Liberibacter asiaticus' or herbivory with Diaphorina citri. Rows represent the genes and columns represent the treatments $(n=30)$. Treatments and genes are organized using two-way hierarchical cluster analysis based on similarities in autoscaled values and correlations, respectively. Values in B and C represent fold change in gene expression compared with healthy plants. 
The current study demonstrated that infection with ' $C a$. L. asiaticus' induced zeaxanthin to a higher level in citrus leaves. Zeaxanthin plays a photoprotection role (Nayak et al. 2001; Niyogi et al. 1997). In oxygenic photosynthetic eukaryotes such as green algae, the xanthophyll pigments such as zeaxanthin are bound with chlorophyll molecules to integral membrane proteins (Green and Durnford 1996; Grossman et al. 1995). This complex provides an important functional role in photosynthetic light-harvesting complexes, converting the light energy into chemical energy (Niyogi et al. 1997). For example, zeaxanthin plays a role in protecting Chlamydomonas reinhardtii, a single-celled green alga, from the photo-oxidative effect (Niyogi et al. 1997). In citrus leaves, the increase in zeaxanthin might be a result of enhanced biosynthesis of $\beta$-arm carotenoids; the gene expression of CitCHYbs was especially upregulated in the presence of ' $\mathrm{Ca}$. L. asiaticus'. Another reason for the accumulation of zeaxanthin could be due to the conversion of violaxanthin by CitVDE, which was upregulated in the presence of ' $\mathrm{Ca}$. L. asiaticus' (Sajilata et al. 2008; Wu et al. 2014). Additionally, the increase in zeaxanthin levels in ' $C a$. L. asiaticus'-infected plants was associated with a decrease in chlorophyll pigments, together resulting in alteration of the pigment composition in citrus leaves. Xanthophylls were a big proportion of total leaf pigments in ' $\mathrm{Ca}$. L. asiaticus'-infected plants (more than half) compared with the control (approximately one-third).

More importantly, our findings showed that ' $\mathrm{Ca}$. L. asiaticus' infection significantly induced $\mathrm{ABA}$ concentration (up to 13fold) in citrus plants. The accumulation of $\mathrm{ABA}$ in ' $\mathrm{Ca}$. L. asiaticus'-infected leaves presumably was due to an increased availability of its precursor, zeaxanthin, as well as the upregulation of gene expression for ABA-biosynthetic genes (CitNSY, CitNCED, CitABA2, and CitAAO3). In other pathosystems, ABA accumulated at a higher level in the infection site of viral (Alazem et al. 2014), fungal (Sánchez-Vallet et al. 2012; Schmidt et al. 2008), and bacterial pathogens (de Torres-Zabala et al. 2007; Rosales and Burns 2011), and was associated with tolerance for those pathogens (Bari and Jones 2009; de TorresZabala et al. 2007; Robert-Seilaniantz et al. 2007). For example, ABA-deficient mutants were more susceptible to bacterial infection with Pseudomonas syringae pv. tomato DC3000 (Melotto et al. 2006; Robert-Seilaniantz et al. 2007). Likewise, the overexpression of CONSTITUTIVE DISEASE SUSCEPTIBILITY2-1D (cds2-1D) in NCED5 mutant showed higher levels of ABA and induced resistance to Alternaria brassicicola in Arabidopsis plants (Fan et al. 2009). Furthermore, Ton and Mauch-Mani (2004) showed that exogenous treatment of Arabidopsis with ABA induced resistance against $A$. brassicicola and Plectosphaerella cucumerina. ABA modulated the plant defenses through the activation of stomatal closure (Melotto et al. 2006; Uraji et al. 2012) or by stimulating callose deposition (Ton and Mauch-Mani 2004). In citrus, ABA accumulation was also observed in citrus flowers challenged with Colletotrichum acutatum (Lahey et al. 2004) and in HLBinfected fruit (Rosales and Burns 2011). Additionally, ABA induced leaf yellowing in rice (Kusaba et al. 2007). Nevertheless, the ABA role in plant defense is very complicated and can differ among different pathosystems (Bari and Jones 2009). Based on these facts, our findings suggest that ABA may play a role in HLB symptom development but the mechanism regarding this is still unclear and requires more investigations.

On the other hand, our results clearly showed that, out of 15 detected pigments, 9 were decreased in $D$. citri-infested plants. Four compounds remained the same ( $\alpha$-cryptoxanthin, cis-violaxanthin, zeaxanthin, and isolutein), and only chlorophyllide $a$ was increased after $D$. citri infestation. As in the control plants, chlorophylls were the most abundant pigments in D. citri-infested plants (approximately 50\%). Many studies showed a significant reduction in total chlorophyll and total carotenoid content after herbivore attack (Blanchfield et al. 2007, 2005; Kumar and Sharma 2014). For example, the leaves of 'Pinot Noir' and 'Cabernet Sauvignon' grapevines (Vitis vinifera) infested by grape phylloxera (Daktulosphaira vitifoliae) were significantly lower in total chlorophyll and total carotenoid content in field trials, and 'Shiraz' grapevines showed further reduction in both chlorophylls and carotenes in greenhouse trials (Blanchfield et al. 2007, 2005). Diaphorina citri, however, feeds on the phloem of young shoots of citrus trees by piercing rather than chewing and, thus, does not damage the leaves as severely as other forms of herbivory. Nevertheless, chlorophyllide $a$ level was increased by $D$. citri feeding, indicating that chlorophyllase was stimulated by cellular disruption.

Likewise, the chlorophyll and carotenoid contents of guava (Dalbergia sissoo) were reduced after infestation by Aonidiella orientalis compared with the healthy plants (Kumar and Sharma 2014). A significant reduction in relative chlorophyll content in tomato plants (S. lycopersicum) after infestation with a high density of the mealybug Phenacoccus solenopsis (Huang et al. 2013) provides more evidence that herbivory alone can alter chlorophyll content. Furthermore, a significant loss of both chlorophyll $a$ and chlorophyll $b$ in four Fabaceae species-faba bean (Vicia faba L.), clover (Trifolium pretense L.), pea (Pisum sativum L.), and alfalfa (Medicago sativa $\mathrm{L}$.) —after feeding by pea aphids (Acyrthosiphon pisum) (Goławska et al. 2010) has been reported. Additionally, attack by adults of chrysomelid flea beetles (Podagrica spp.) caused a significant reduction in chlorophyll concentrations of okra plants (Abelmoschus esculentus L.) (Ekoja et al. 2012).

In this study, challenging citrus plants with Diaphorina citri resulted in higher levels of chlorophyllide $a$ (almost threefold) compared with the control. Additionally, CitCBR and CitChlase, the key enzymes in chlorophyllide production from chlorophyll molecules, were upregulated in D. citri-infested plants (Tsuchiya et al. 1999). Taken together, these findings suggest that chlorophyllide $a$ and CitChlase are implicated in the citrus defense against $D$. citri. Chlorophyllide, one of the tetrapyrrole pigments, shows toxicity toward fungal and animal cells (Kariola et al. 2005; Meskauskiene et al. 2001) and could be a part of the defense system (Hu et al. 2015). For example, downregulation of chlorophyllase (AtCLH) reduced Arabidopsis resistance to the fungus Alternaria brassicicola (Kariola et al. 2005). Additionally, the treatment of Arabidopsis plants with exogenous chlorophyllide or the overexpression of $C L H$ increased the toxicity against Spodoptera litura larvae (Hu et al. 2015). Furthermore, the application of methyl jasmonate, a derivative of jasmonic acid (JA), increased the expression levels of AtChlase in Arabidopsis plants (Tsuchiya et al. 1999) and OsNYC1 in rice leaves (Kusaba et al. 2007). Both Chlase and NYCl promote the conversion of chlorophyll to chlorophyllide. Interestingly, JA was increased in D. citri-infected plants (data not shown); thus, we hypothesize that chlorophyllide is associated with a JA-mediated pathway in citrus.

Based on these findings, a hypothetical model demonstrating how ' $C a$. L. asiaticus' or $D$. citri affect the citrus leaf pigments and their roles in stimulating citrus response system was proposed (Fig. 8). We hypothesize that both ' $\mathrm{Ca}$. L. asiaticus' and $D$. citri affect the leaf pigments but through two different mechanisms. (i) Our findings showed that ' $\mathrm{Ca}$. L. asiaticus' decreased all chlorophyll and carotenoid compounds but resulted in accumulation of zeaxanthin. In addition to the photoprotective role of zeaxanthin, it is also the precursor of ABA, which is considered a stress-associated phytohormone. Therefore, both chlorophyll degradation and $\mathrm{ABA}$ accumulation are implicated 
in HLB symptom development (Fig. 8A). However, more investigations are required to clarify whether ' $\mathrm{Ca}$. L. asiaticus' directly manipulates the citrus pigments or it is a plant response to the attack. (ii) In this study, D. citri herbivory reduced all chlorophyll and most carotenoid pigments but led to an accumulation of chlorophyllide $a$. Chlorophyllide $a$ is implicated in the citrus defense against $D$. citri. Together, chlorophyll and carotenoid biosynthesis reduction are implicated in the development of HLB symptoms (Fig. 8B). Based on this hypothetical model, while ' $C a$. L. asiaticus' and $D$. citri alter citrus pigments, citrus plants try to defend themselves using a multifaceted defense system, including zeaxanthin, chlorophyllide $a$, JA, and ABA production. The pigment-dependent defense system may vary based on the stressor type (' $\mathrm{Ca}$. L. asiaticus', D. citri, or both together). More studies are needed to investigate these complex systems. Complete understanding of these mechanisms may be useful for the study of other vectorborne diseases.

\section{MATERIALS AND METHODS}

Plant materials and growth conditions.

Citrus sinensis (L.) Osbeck (Valencia sweet orange) trees were used in this study. All trees were approximately $80 \pm 5 \mathrm{~cm}$ tall, approximately 18 months old, and maintained in an approved United States Department of Agriculture-Animal and Plant Health Inspection Service, Centers for Disease Controlsecured greenhouse at $28 \pm 3^{\circ} \mathrm{C}, 65 \pm 5 \%$ relative humidity, and a photocycle of $16 \mathrm{~h}$ of light and $8 \mathrm{~h}$ of darkness at the Citrus Research and Education Center, University of Florida, Lake Alfred. Weekly, plants were irrigated twice and fertilized once using 20-10-20 NPK fertilizer (Peter's fertilizer, Allentown, PA, U.S.A.). In this study, four treatments (five replicates for each) were tested: control, ' $C a$. L. asiaticus'-infected, $D$. citri-infested, and double-attacked ('Ca. L. asiaticus'-infected and D. citriinfested) trees. To obtain the ' $C a$. L. asiaticus'-infected trees, 10month-old, HLB-free Valencia sweet orange trees were graft inoculated with budwoods from a polymerase chain reaction (PCR)-positive HLB source (HLB-infected citrus trees) and maintained in the same conditions as described above. Upon initial symptom development, approximately 7 months later, the infection with ' $C a$. L. asiaticus' was confirmed by PCR (Tatineni et al. 2008). To obtain D. citri-infested plants, 100 healthy D. citri (previously reared on Bergera koenegii, a nonhost for ' $\mathrm{Ca}$. L. asiaticus') were transferred to a healthy citrus plant, which was trimmed 1 week prior to the infestation to enhance the production of new flushes. Infested plants were caged individually for 1 month. To obtain the double-attacked plants, ' $C a$. L. asiaticus'-infected trees, with enhanced flushing as described above, were exposed to 100 ' $C a$. L. asiaticus'-negative adult psyllids per tree for 1 month All plants used in this study, with or without $D$. citri infestations, were caged individually using insect-rearing cages ( 60 by 60 by $90 \mathrm{~cm}$ ) and maintained in the same conditions as described above. One month later, both D. citri-infested and double-attacked plants were cleaned from all D. citri stages (nymphs and adults). For sampling, three symptomatic leaves were collected per tree from different positions. Collected leaves were from different ages; a juvenile leaf from the top, moderate-aged leaf from the middle, and mature leaf from the lower part of the plant. The collected leaves were chopped, mixed together, and immediately kept on ice. Plant materials were kept at $-80^{\circ} \mathrm{C}$ until analysis.

\section{Extraction of citrus leaf pigments.}

Plant tissues were placed into a frozen mortar and pestle and ground in liquid nitrogen into fine powder; then, citrus leaf

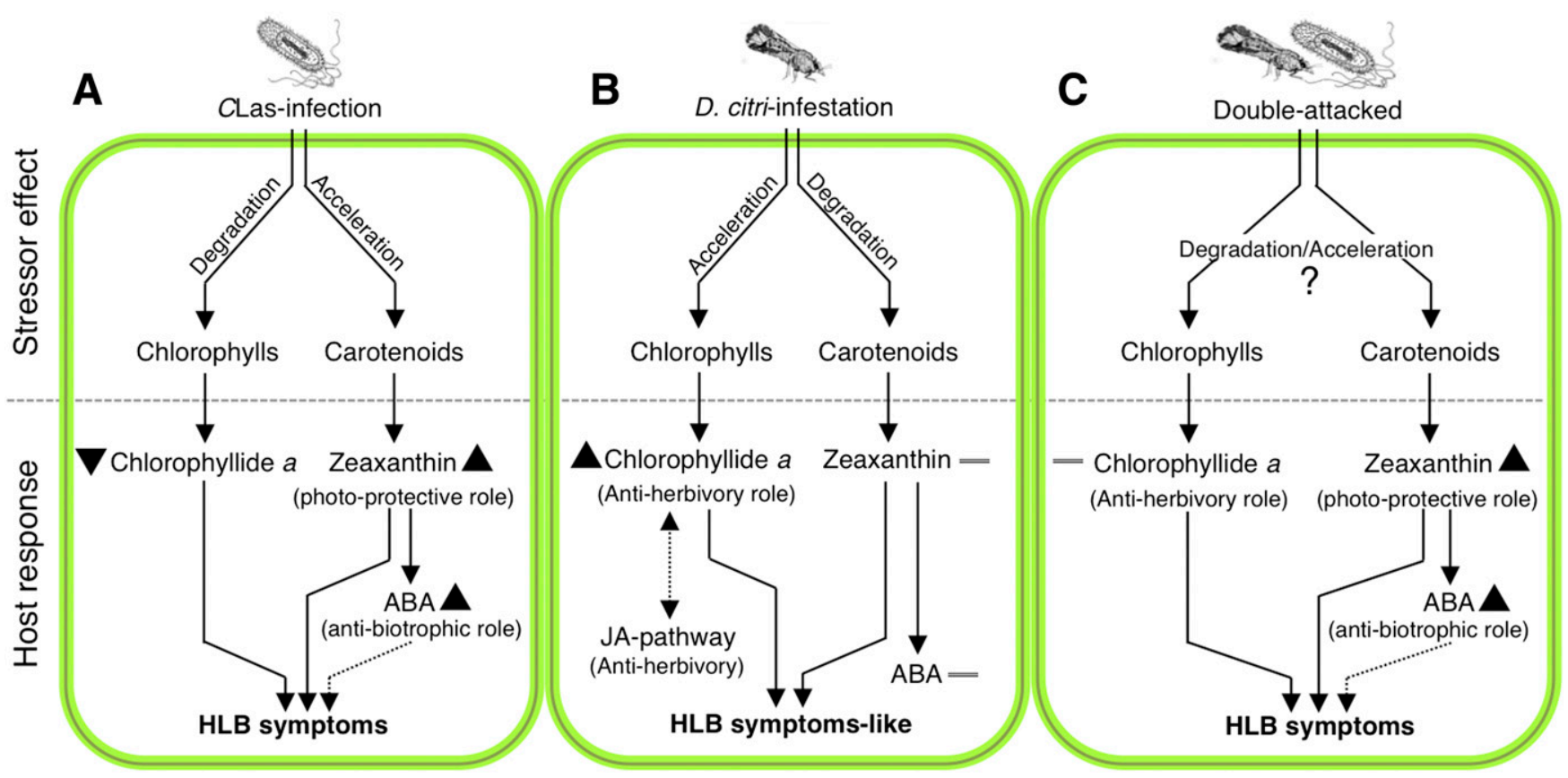

Fig. 8. Schematic representation of proposed model for the effect of infection with 'Candidatus Liberibacter asiaticus' (CLas) or infestation with Diaphorina citri on Valencia sweet orange (Citrus sinensis) leaf pigments and citrus response. A, 'Ca. L. asiaticus' might reduce most citrus leaf pigments (chlorophylls and carotenoids) but result in zeaxanthin accumulation and development of huanglongbing (HLB) symptoms. Zeaxanthin is a photoprotector pigment and precursor of abscisic acid (ABA), which is a stress-associated phytohormone. B, D. citri might induce the development of HLB-like symptoms via decreasing both carotenoid and chlorophyll biosynthesis but causing accumulation of chlorophyllide $a$, which induces a jasmonic-acid-mediated pathway; both together have an antiherbivory role in citrus. C, Presence of both stressors results in ABA accumulation and symptom development in a mechanism similar to ' $\mathrm{Ca}$. L. asiaticus' infection. Up arrow $(\uparrow)$ indicates increasing, down arrow $(\downarrow)$ indicates decreasing, and equal sign $(=)$ indicates no changes in compound levels. Dotted lines with arrows represent hypothetical mechanisms or uncharacterized elements. 
pigments were extracted according to the methods of Norris and associates (1995), with slight modifications as follows. Briefly, approximately $0.1 \mathrm{~g}$ of ground material was transferred to a $1.5-\mathrm{ml}$ amber tube. For each sample, $400 \mu \mathrm{l}$ of $80 \%$ acetone was added, followed by $240 \mu \mathrm{l}$ of ethyl acetate, and vortexed for $30 \mathrm{~s}$. Samples were left in the dark on ice for $10 \mathrm{~min}$ and the vortexing was repeated twice. Later, $280 \mu \mathrm{l}$ of water was added and the mixture was centrifuged at $8,500 \times g$ for $5 \mathrm{~min}$ at $4^{\circ} \mathrm{C}$. Then, the upper layer was transferred to a new 500- $\mu$ l amber tube and dried under a nitrogen stream. The dried extract was resuspended in $200 \mu \mathrm{l}$ of ethyl acetate and analyzed immediately by HPLC or stored in the dark at $-20^{\circ} \mathrm{C}$.

\section{HPLC analysis.}

HPLC analysis of citrus leaf pigments was carried out as described previously by Wei and associates $(2014 a, b)$. The HPLC system consisted of an Agilent 1200 system with photodiode array detector (Agilent Technologies, Santa Clara, CA, U.S.A.). Chromatographic separation was performed using a C30 YMC carotenoid column, 250 by $4.6 \mathrm{~mm}$ i.d., S-5 $\mu \mathrm{m}$ (YMC America, Allentown, PA, U.S.A.). The mobile phase composition and the gradient profile were as described by Mouly and associates (1999), with slight modifications. Briefly, a stepwise linear elution gradient of methanol, methyl tert-butyl ether, and water and was used (Table 2). The column temperature was adjusted at $25^{\circ} \mathrm{C}$, mobile phase flow rate was $1 \mathrm{ml} \mathrm{min}^{-1}$, and injection volume was $20 \mu \mathrm{l}$. Absorbance of the various citrus leaf pigments and peak responses were monitored at several spectral wavelengths $(230,278,350,430$, and $486 \mathrm{~nm})$. The HPLC output data were analyzed using ChemStation software (version B.03.02; Agilent Technologies). Peaks were first identified by comparing experimental retention times and UV-visible spectra with that in published literature (Table 1), as well as with authentic standards. Chlorophyll $a$, chlorophyll $b, \alpha$-carotene, $\beta$-carotene, lutein, and zeaxanthin were obtained from Sigma-Aldrich (St. Louis) and used to establish a calibration curve from which to calculate the pigment concentration in the extract for those compounds. The rest of the pigments were calculated tentatively using the lutein calibration curve.

\section{ABA determination using ELISA.}

ABA was determined according to Ross and associates (1987), with slight modifications. Briefly, ABA was extracted from $300 \mathrm{mg}$ of leaf tissue with $80 \%$ methanol containing butylated hydroxytoluene (as an antioxidant) at $100 \mathrm{mg} \mathrm{liter}^{-1}$ for $18 \mathrm{~h}$ at $4^{\circ} \mathrm{C}$ in the dark. The extract was centrifuged at $8,500 \times g$ for $10 \mathrm{~min}$ at $4^{\circ} \mathrm{C}$. The supernatant was recovered and purified using a Sep-Pak $\mathrm{C}_{18}$ classic short cartridge (360 mg of Sorbent per cartridge, 55- to $105-\mu \mathrm{m}$ particle size) (Waters, Milford, MA, U.S.A.), connected to a Titan2 5- $\mu$ m nylon filter (SUNSri; Thermo Fisher Scientific, Rockwood, TN, U.S.A.). The eluted samples were dried under a nitrogen stream to $20 \mu \mathrm{l}$, then

Table 2. Gradient profile used in high-performance liquid chromatography for citrus leaf pigment determination

\begin{tabular}{lccc}
\hline & \multicolumn{3}{c}{ Mobile phase (\% vol) } \\
\cline { 2 - 4 } Time (min) $^{\mathbf{y}}$ & MTBE $^{\mathbf{z}}$ & Methanol & Water \\
\hline 0 & 5 & 90 & 5 \\
12 & 5 & 95 & 0 \\
25 & 11 & 89 & 0 \\
40 & 25 & 75 & 0 \\
60 & 50 & 50 & 0 \\
62 & 5 & 90 & 5 \\
65 & 5 & 90 & 5 \\
\hline
\end{tabular}

y Equilibrating time $13 \mathrm{~min}$.

${ }^{\mathrm{z}}$ Methyl tert-butyl ether. diluted with $180 \mu \mathrm{l}$ of $1 \times$ TRIS-buffered saline (Tris base at $0.53 \mathrm{~g} \mathrm{liter}^{-1}$, Tris $\mathrm{HCl}$ at $3.25 \mathrm{~g} \mathrm{liter}^{-1}, \mathrm{NaCl}$ at $5.84 \mathrm{~g} \mathrm{liter}^{-1}$, and $\mathrm{MgCl}_{2}$ at $0.2 \mathrm{~g} \mathrm{liter}^{-1}, \mathrm{pH}$ 7.5). Samples were analyzed and quantified by competitive direct ELISA using a Phytodetek ABA test kit (Agdia Inc., Elkhart, IN, USA). The ELISA procedure used in this study was performed following the manufacturer's instructions. ABA concentration was estimated using the standard curve prepared in the same immunoassay plate.

\section{Colorimetric determination of starch and sucrose.}

Starch and sucrose were extracted according to (Cimò et al. 2013), with slight modifications. Briefly, starch and sucrose were extracted from $100 \pm 3 \mathrm{mg}$ of ground leaf tissues using $500 \mu \mathrm{l}$ of distilled water and vortexed for $30 \mathrm{~s}$. The extract was boiled in a water bath for $10 \mathrm{~min}$, then vortexed for $10 \mathrm{~s}$. Following centrifugation at low speed $(650 \times g)$, the supernatant was divided into two portions: $300 \mu \mathrm{l}$ for starch determination (Cimò et al. 2013) and $100 \mu \mathrm{l}$ for sucrose determination (van Handel 1968). Starch was determined by monitoring the color change at $595 \mathrm{~nm}$ using a microplate spectrophotometer (Model 680; Bio-Rad Laboratories, Hercules, CA, U.S.A.). Rice starch from Sigma-Aldrich was used as a standard. Sucrose determination was accomplished at $620 \mathrm{~nm}$ using PharmaSpect ultraviolet 1700 spectrophotometer (Shimadzu Corporation, Kyoto, Japan).

\section{Gene expression analysis.}

Total RNA was extracted using TriZol reagent (Ambion, Life Technologies, Carlsbad, CA, U.S.A.). A NanoDrop 2000 spectrophotometer (Thermo Fisher Scientific) was used to estimate the quantity and quality of isolated RNA. For synthesizing cDNA, a SuperScript first-strand synthesis system (Invitrogen, Carlsbad, CA, U.S.A.) with random hexamer primers was used as described by the manufacturer's instructions. SYBR Green PCR master mix (Applied Biosystems, Carlsbad, CA, U.S.A.) was used to perform quantitative PCR on an ABI 7500 Real-Time PCR System (Applied Biosystems). For each treatment, two technical replicates per biological replicate and five biological replicates per treatment were analyzed in three replicates. Primers for 48 genes were used to measure the gene expression. The $2^{-\Delta \Delta \mathrm{CT}}$ method was used to determine the relative expression of genes (Livak and Schmittgen 2001). EF1, $F$-box, GAPCl, and $S A N D$ were used as endogenous genes (reference genes) to normalize the data of gene expression (Mafra et al. 2012; Wei et al. 2014a,b).

\section{Statistical analysis.}

For HPLC, five biological and two technical replicates per treatment were analyzed. All pigment concentrations were statistically analyzed using the analysis of variance. Post hoc pairwise comparisons between the four studied treatments were performed using a Tukey-Kramer honestly significant different test. PCA associated with loading plots were generated to differentiate between treatment. Two-way HCA was also performed with the means of the matrices for the four studied treatments. Distance and linkage were done using the BrayCurtis similarity measure method (Michie 1982). 3D surface plots were performed among the three pigments groups (as a total for each group) with the matrices of data for the four studied treatments. Multivariate gene similarities were presented as a heat map using the averages of fold change, where gene expression in healthy plants considered 1 , combined with two-way HCA as described above.

\section{ACKNOWLEDGMENTS}

We thank S. E. Jones and L. Lindsey for their assistance with the psyllid colonies and F. Hijaz for technical assistance in HPLC. 


\section{LITERATURE CITED}

Alazem, M., Lin, K.-Y., and Lin, N.-S. 2014. The abscisic acid pathway has multifaceted effects on the accumulation of Bamboo mosaic virus. Mol. Plant-Microbe Interact. 27:177-189.

Armstrong, G. A., and Hearst, J. E. 1996. Carotenoids 2: Genetics and molecular biology of carotenoid pigment biosynthesis. FASEB J. 10: 228-237.

Bari, R., and Jones, J. D. G. 2009. Role of plant hormones in plant defence responses. Plant Mol. Biol. 69:473-488.

Bauernfeind, J. C. 1972. Carotenoid vitamin A precursors and analogs in foods and feeds. J. Agric. Food Chem. 20:456-473.

Blanchfield, A., Powell, K., and Robinson, S. 2007. Preliminary investigations of pigment responses to phylloxera infestation. Acta Hortic. 733:123-133.

Blanchfield, A. L., Robinson, S. A., Renzullo, L. J., and Powell, K. S. 2005 Phylloxera infested grapevines have reduced chlorophyll and increased photoprotective pigment content-Can leaf pigment composition aid pest detection? Funct. Plant Biol. 33:507-517.

Bové, J. M. 2006. Huanglongbing: A destructive, newly-emerging, centuryold disease of citrus. J. Plant Pathol. 88:7-37.

Bové, J. M., and Ayres, A. J. 2007. Etiology of three recent diseases of citrus in São Paulo State: Sudden death, variegated chlorosis and huanglongbing. IUBMB Life 59:346-354.

Cazzonelli, C. I. 2011. Carotenoids in nature: Insights from plants and beyond. Funct. Plant Biol. 38:833-847.

Cimò, G., Lo Bianco, R., Gonzalez, P., Bandaranayake, W., Etxeberria, E., and Syvertsen, J. P. 2013. Carbohydrate and nutritional responses to stem girdling and drought stress with respect to understanding symptoms of huanglongbing in citrus. HortScience 48:920-928.

Coletta-Filho, H. D., Targon, M. L. P. N., Takita, M. A., De Negri, J. D., Pompeu, J., Machado, M. A., do Amaral, A. M., and Muller, G. W. 2004 First report of the causal agent of huanglongbing ("Candidatus Liberibacter asiaticus") in brazil. Plant Dis. 88:1382.

Cunningham, F. X., and Gantt, E. 1998. Genes and enzymes of carotenoid biosynthesis in plants. Annu. Rev. Plant Physiol. Plant Mol. Biol. 49: 557-583.

da Graça, J. V. 1991. Citrus greening disease. Annu. Rev. Phytopathol. 29: 109-136.

da Graça, J. V., and Korsten, L. 2004. Citrus Huanglongbing: Review, present status and future strategies. Pages 229-245 in: Diseases of Fruits and Vegetables, Vol. I. S. A. M. H. Naqvi, ed. Springer, Dordrecht, The Netherlands

de Torres-Zabala, M., Truman, W., Bennett, M. H., Lafforgue, G., Mansfield, J. W., Rodriguez Egea, P., Bögre, L., and Grant, M. 2007. Pseudomonas syringae pv. tomato hijacks the Arabidopsis abscisic acid signalling pathway to cause disease. EMBO J. 26:1434-1443.

do Carmo Teixeira, D., Danet, J. L., Eveillard, S., Martins, E. C., de Jesus Junior, W. C., Yamamoto, P. T., Lopes, S. A., Bassanezi, R. B., Ayres, A. J., Saillard, C., and Bové, J. M. 2005a. Citrus huanglongbing in São Paulo State, Brazil: PCR detection of the 'Candidatus' Liberibacter species associated with the disease. Mol. Cell. Probes 19:173-179.

do Carmo Teixeira, D., Saillard, C., Eveillard, S., Danet, J. L., da Costa, P. I., Ayres, A. J., and Bové, J. 2005b. 'Candidatus Liberibacter americanus', associated with citrus huanglongbing (greening disease) in São Paulo State, Brazil. Int. J. Syst. Evol. Microbiol. 55:1857-1862

Edelenbos, M., Christensen, L. P., and Grevsen, K. 2001. HPLC determination of chlorophyll and carotenoid pigments in processed green pea cultivars (Pisum sativum L.). J. Agric. Food Chem. 49: 4768-4774.

Ekoja, E. E., Pitan, O. O. R., and Ataiyese, M. O. 2012. Physiological response of okra to flea beetle herbivory as measured by leaf loss, chlorophyll disruption, and dry matter yield. Int. J. Veg. Sci. 18: 171-181.

Fan, J., Hill, L., Crooks, C., Doerner, P., and Lamb, C. 2009. Abscisic acid has a key role in modulating diverse plant-pathogen interactions. Plant Physiol. 150:1750-1761.

Goławska, S., Krzyżanowski, R., and Łukasik, I. 2010. Relationship between aphid infestation and chlorophyll content in Fabaceae species. Acta Biol. Cracov. Ser. Bot. 52:76-80.

Gottwald, T. R. 2010. Current epidemiological understanding of citrus Huanglongbing. Annu. Rev. Phytopathol. 48:119-139.

Gottwald, T. R., Aubert, B., and Zhao, X.-Y. 1989. Preliminary analysis of citrus greening (Huanglungbin) epidemics in the People's Republic of China and French Reunion Island. Phytopathology 79:687-693.

Gough, S. P., Westergren, T., and Hansson, M. 2003. Chlorophyll biosynthesis in higher plants. Regulatory aspects of 5-aminolevulinate formation. J. Plant Biol. 46:135-160.
Green, B. R., and Durnford, D. G. 1996. The chlorophyll-carotenoid proteins of oxygenic photosynthesis. Annu. Rev. Plant Physiol. Plant Mol. Biol. 47:685-714.

Grossman, A. R., Bhaya, D., Apt, K. E., and Kehoe, D. M. 1995. Lightharvesting complexes in oxygenic photosynthesis: Diversity, control, and evolution. Annu. Rev. Genet. 29:231-288.

Hoy, M. A., and Nguyen, R. 2000. Classical biological control of Asian citrus psylla. Citrus Ind. 81:48-50.

Hu, X., Makita, S., Schelbert, S., Sano, S., Ochiai, M., Tsuchiya, T., Hasegawa, S. F., Hörtensteiner, S., Tanaka, A., and Tanaka, R. 2015. Reexamination of chlorophyllase function implies its involvement in defense against chewing herbivores. Plant Physiol. 167:660-670.

Huang, J., Zhang, P.-J., Zhang, J., Lu, Y.-B., Huang, F., and Li, M.-J. 2013. Chlorophyll content and chlorophyll fluorescence in tomato leaves infested with an invasive mealybug, Phenacoccus solenopsis (Hemiptera: Pseudococcidae). Environ. Entomol. 42:973-979.

Jagoueix, S., Bove, J.-M., and Garnier, M. 1994. The phloem-limited bacterium of greening disease of citrus is a member of the alpha subdivision of the Proteobacteria. Int. J. Syst. Bacteriol. 44:379-386.

Kangasjärvi, S., Neukermans, J., Li, S., Aro, E.-M., and Noctor, G. 2012. Photosynthesis, photorespiration, and light signalling in defence responses. J. Exp. Bot. 63:1619-1636.

Kariola, T., Brader, G., Li, J., and Palva, E. T. 2005. Chlorophyllase 1, a damage control enzyme, affects the balance between defense pathways in plants. Plant Cell 17:282-294.

Kato, M. 2012. Mechanism of carotenoid accumulation in citrus fruit. J. Jpn. Soc. Hortic. Sci. 81:219-233.

Kumar, A., Gul, M. Z., Zeeshan, A., Bimolata, W., Qureshi, I. A., and Ghazi, I. A. 2013. Differential antioxidative responses of three different rice genotypes during bacterial blight infection. Aust. J. Crop Sci. 7: 1893-1900.

Kumar, H., and Sharma, S. 2014. Determination of chlorophyll and carotenoid loss in Dalbergia sissoo caused by Aonidiella orientalis (Newstead) [Homoptera: Coccoidea: Diaspididae]. J. Entomol. Zool. Stud. 2:104-106.

Kusaba, M., Ito, H., Morita, R., Iida, S., Sato, Y., Fujimoto, M., Kawasaki, S., Tanaka, R., Hirochika, H., Nishimura, M., and Tanaka, A. 2007. Rice NON-YELLOW COLORING1 is involved in light-harvesting complex II and grana degradation during leaf senescence. Plant Cell 19: $1362-1375$

Lahey, K. A., Yuan, R., Burns, J. K., Ueng, P. P., Timmer, L. W., and Chung, K. R. 2004. Induction of phytohormones and differential gene expression in citrus flowers infected by the fungus Colletotrichum acutatum. Mol. Plant-Microbe Interact. 17:1394-1401

Livak, K. J., and Schmittgen, T. D. 2001. Analysis of relative gene expression data using real-time quantitative PCR and the $2^{-\Delta \Delta C T}$ method. Methods 25:402-408.

Lobato, A., Gonçalves-Vidigal, M., Vidigal Filho, P., Andrade, C., Kvitschal, M., and Bonato, C. 2010. Relationships between leaf pigments and photosynthesis in common bean plants infected by anthracnose. N. Z. J. Crop Hortic. Sci. 38:29-37.

Mafra, V., Kubo, K. S., Alves-Ferreira, M., Ribeiro-Alves, M., Stuart, R. M., Boava, L. P., Rodrigues, C. M., and Machado, M. A. 2012 Reference genes for accurate transcript normalization in citrus genotypes under different experimental conditions. PLoS One 7:e31263.

Matsumoto, H., Ikoma, Y., Kato, M., Kuniga, T., Nakajima, N., and Yoshida, T. 2007. Quantification of carotenoids in citrus fruit by LC-MS and comparison of patterns of seasonal changes for carotenoids among citrus varieties. J. Agric. Food Chem. 55:2356-2368.

Melotto, M., Underwood, W., Koczan, J., Nomura, K., and He, S. Y. 2006. Plant stomata function in innate immunity against bacterial invasion. Cell 126:969-980.

Meskauskiene, R., Nater, M., Goslings, D., Kessler, F., op den Camp, R., and Apel, K. 2001. FLU: A negative regulator of chlorophyll biosynthesis in Arabidopsis thaliana. Proc. Natl. Acad. Sci. USA 98: 12826-12831.

Michie, M. G. 1982. Use of the Bray-Curtis similarity measure in cluster analysis of foraminiferal data. J. Int. Assoc. Math. Geol. 14:661-667.

Milavec, M., Kovaç, M., and Ravnikar, M. 1999. Photosynthetic pigments in potato plants (Solanum tuberosum L.) cv. Igor after primary infection with Potato virus $\mathrm{Y}^{\mathrm{NTN}}$. Phyton 39:265-269.

Milenković, S. M., Zvezdanović, J. B., Anđelković, T. D., and Marković, D. Z. 2012. The identification of chlorophyll and its derivatives in the pigment mixtures: HPLC-chromatography, visible and mass spectroscopy studies. Adv. Technol. 1:16-24.

Mishra, A., Karimi, D., Ehsani, R., and Albrigo, L. G. 2011. Evaluation of an active optical sensor for detection of Huanglongbing (HLB) disease. Biosyst. Eng. 110:302-309. 
Mouly, P. P., Gaydou, E. M., Lapierre, L., and Corsetti, J. 1999. Differentiation of several geographical origins in single-strength Valencia orange juices using quantitative comparison of carotenoid profiles. J. Agric. Food Chem. 47:4038-4045.

Nayak, L., Raval, M. K., Biswal, B., and Biswal, U. C. 2001. Photoprotection of green leaves by zeaxanthin, a two-channel process. Curr. Sci. 81:1165-1166.

Niyogi, K. K., Björkman, O., and Grossman, A. R. 1997. The roles of specific xanthophylls in photoprotection. Proc. Natl. Acad. Sci. U.S.A. 94:14162-14167.

Norris, S. R., Barrette, T. R., and DellaPenna, D. 1995. Genetic dissection of carotenoid synthesis in Arabidopsis defines plastoquinone as an essential component of phytoene desaturation. Plant Cell 7:2139-2149.

Pazarlar, S., Gümüs, M., and Öztekİn, G. B. 2013. The effects of Tobacco mosaic virus infection on growth and physiological parameters in some pepper varieties (Capsicum annuиm L.). Not. Bot. Horti Agrobot. ClujNapoca 41:427-433.

Planet, P., Jagoueix, S., Bové, J. M., and Garnier, M. 1995. Detection and characterization of the African citrus greening liberobacter by amplification, cloning, and sequencing of the rplKAJL-rpoBC operon. Curr. Microbiol. 30:137-141.

Prokopová, J., Mieslerová, B., Hlaváčková, V., Hlavinka, J., Lebeda, A., Nauš, J., and Špundová, M. 2010a. Changes in photosynthesis of Lycopersicon spp. plants induced by tomato powdery mildew infection in combination with heat shock pre-treatment. Physiol. Mol. Plant Pathol. 74:205-213.

Prokopová, J., Spundová, M., Sedlárová, M., Husicková, A., Novotný, R., Dolezal, K., Naus, J., and Lebeda, A. 2010b. Photosynthetic responses of lettuce to downy mildew infection and cytokinin treatment. Plant Physiol. Biochem. 48:716-723.

Rahman, H., Alam, M. M., Bhyan, S. B., and Akanda, A. M. 2008. Alteration of cellular pigments of papaya leaves infected with seven symptomatic isolates of PRSV-P. J. Plant Sci. 3:69-76.

Reinbothe, C., El Bakkouri, M., Buhr, F., Muraki, N., Nomata, J., Kurisu, G., Fujita, Y., and Reinbothe, S. 2010. Chlorophyll biosynthesis: Spotlight on protochlorophyllide reduction. Trends Plant Sci. 15:614-624.

Robert-Seilaniantz, A., Navarro, L., Bari, R., and Jones, J. D. 2007. Pathological hormone imbalances. Curr. Opin. Plant Biol. 10:372-379.

Rodrigo, M.-J., Marcos, J. F., and Zacarías, L. 2004. Biochemical and molecular analysis of carotenoid biosynthesis in flavedo of orange (Citrus sinensis L.) during fruit development and maturation. J. Agric. Food Chem. 52:6724-6731.

Rosales, R., and Burns, J. K. 2011. Phytohormone changes and carbohydrate status in sweet orange fruit from huanglongbing-infected trees. J. Plant Growth Regul. 30:312-321.

Ross, G. S., Elder, P. A., McWha, J. A., Pearce, D., and Pharis, R. P. 1987. The development of an indirect enzyme linked immunoassay for abscisic Acid. Plant Physiol. 85:46-50.

Rouseff, R., Raley, L., and Hofsommer, H.-J. 1996. Application of diode array detection with a C-30 reversed phase column for the separation and identification of saponified orange juice carotenoids. J. Agric. Food Chem. 44:2176-2181.

Sagaram, M., Burns, J. K., and Alfred, L. 2009. Leaf chlorophyll fluorescence parameters and Huanglongbing. J. Am. Soc. Hortic. Sci. 134:194-201.

Sajilata, M. G., Singhal, R. S., and Kamat, M. Y. 2008. The carotenoid pigment zeaxanthin: A review. Compr. Rev. Food Sci. Food Saf. 7:29-49.

Sánchez-Vallet, A., López, G., Ramos, B., Delgado-Cerezo, M., Riviere, M.-P., Llorente, F., Fernández, P. V., Miedes, E., Estevez, J. M., Grant, M., and Molina, A. 2012. Disruption of abscisic acid signaling constitutively activates Arabidopsis resistance to the necrotrophic fungus Plectosphaerella cucumerina. Plant Physiol. 160:2109-2124.

Schmidt, K., Pflugmacher, M., Klages, S., Mäser, A., Mock, A., and Stahl, D. J. 2008. Accumulation of the hormone abscisic acid (ABA) at the infection site of the fungus Cercospora beticola supports the role of ABA as a repressor of plant defence in sugar beet. Mol. Plant Pathol. 9: 661-673.

Schneider, H. 1968. Anatomy of greening diseased sweet orange shoots. Phytopathology 58:1155-1160.

Smith, E. L. 1938. Limiting factors in photosynthesis: Light and carbon dioxide. J. Gen. Physiol. 22:21-35.

Tanaka, R., Kobayashi, K., and Masuda, T. 2011. Tetrapyrrole metabolism in Arabidopsis thaliana. Arabidopsis Book 9:e0145.

Tanaka, R., and Tanaka, A. 2007. Tetrapyrrole biosynthesis in higher plants. Annu. Rev. Plant Biol. 58:321-346.

Tanaka, Y., Sasaki, N., and Ohmiya, A. 2008. Biosynthesis of plant pigments: Anthocyanins, betalains and carotenoids. Plant J. 54:733-749.

Tatineni, S., Sagaram, U. S., Gowda, S., Robertson, C. J., Dawson, W. O., Iwanami, T., and Wang, N. 2008. In planta distribution of 'Candidatus Liberibacter asiaticus' as revealed by polymerase chain reaction (PCR) and real-time PCR. Phytopathology 98:592-599.

Terry, N. 1980. Limiting factors in photosynthesis: I. Use of iron stress to control photochemical capacity in vivo. Plant Physiol. 65:114-120.

Ton, J., and Mauch-Mani, B. 2004. $\beta$-amino-butyric acid-induced resistance against necrotrophic pathogens is based on ABA-dependent priming for callose. Plant J. 38:119-130.

Tsuchiya, T., Ohta, H., Okawa, K., Iwamatsu, A., Shimada, H., Masuda, T., and Takamiya, K. 1999. Cloning of chlorophyllase, the key enzyme in chlorophyll degradation: Finding of a lipase motif and the induction by methyl jasmonate. Proc. Natl. Acad. Sci. U.S.A. 96:15362-15367.

Uraji, M., Katagiri, T., Okuma, E., Ye, W., Hossain, M. A., Masuda, C., Miura, A., Nakamura, Y., Mori, I. C., Shinozaki, K., and Murata, Y. 2012. Cooperative function of PLD $\delta$ and PLD $\alpha 1$ in abscisic acidinduced stomatal closure in Arabidopsis. Plant Physiol. 159:450-460.

van Handel, E. 1968. Direct microdetermination of sucrose. Anal Biochem. 22:280-283.

Vershinin, A. 1999. Biological functions of carotenoids-Diversity and evolution. Biofactors 10:99-104.

von Wettstein, D., Gough, S., and Kannangara, C. G. 1995. Chlorophyll biosynthesis. Plant Cell 7:1039-1057.

Wang, N., and Trivedi, P. 2013. Citrus huanglongbing: A newly relevant disease presents unprecedented challenges. Phytopathology 103: 652-665.

Wei, X., Chen, C., Yu, Q., Gady, A., Yu, Y., Liang, G., and Gmitter, F. G., Jr. 2014a. Comparison of carotenoid accumulation and biosynthetic gene expression between Valencia and Rohde Red Valencia sweet oranges. Plant Sci. 227:28-36.

Wei, X., Chen, C., Yu, Q., Gady, A., Yu, Y., Liang, G., and Gmitter, F. G., Jr. 2014b. Novel expression patterns of carotenoid pathway-related genes in citrus leaves and maturing fruits. Tree Genet. Genomes 10:439-448.

Wu, J., Ji, J., Wang, G., Li, Z., Diao, J., and Wu, G. 2014. Cloning and characterization of a novel $\beta$-carotene hydroxylase gene from Lycium barbarum and its expression in Escherichia coli. Biotechnol. Appl. Biochem. 61:637-645.

Xie, X.-Z., Xue, Y.-J., Zhou, J.-J., Zhang, B., Chang, H., and Takano, M. 2011. Phytochromes regulate SA and JA signaling pathways in rice and are required for developmentally controlled resistance to Magnaporthe grisea. Mol. Plant 4:688-696. 